\title{
Expression of the period Clock Gene within Different Cell Types in the Brain of Drosophila Adults and Mosaic Analysis of these Cells' Influence on Circadian Behavioral Rhythms
}

\author{
John Ewer, ${ }^{1, a}$ Brigitte Frisch, ${ }^{1}$ Melanie J. Hamblen-Coyle, ${ }^{1}$ Michael Rosbash,, ${ }^{1,2}$ and Jeffrey C. Hall' \\ 'Department of Biology and ${ }^{2}$ Howard Hughes Medical Institute, Brandeis University, Waltham, Massachusetts 02254
}

The product of the period (per) gene of Drosophila melanogaster is continuously required for the functioning of the circadian pacemaker of locomotor activity. We have used internally marked mosaics to determine the anatomical locations at which per expression is required for adult rhythmicity, and thus where the fly's circadian pacemaker is likely located in this holometabolous insect.

We first provide a detailed description of the distribution and nature of per-expressing cells in the fly's CNS. Using an antibody to the per gene product, or to that of a reporter of per expression, in conjunction with an antibody to the embryonic lethal-abnormal visual system (elav) gene product-which is used as a marker of neuronal identity-we have experimentally confirmed previously proposed assignments of per-expressing cells to the neuronal and glial classes. Thus, we found that per expression and elav immunoreactivity colocalized in large cells located in the lateral cortex of the central brain, as well as in more dorsally located cells in the posterior central brain. In contrast, we found that cells located at the margins of the cortex and the neuropil, and within the neuropil, as well as smaller cortical cells found throughout the brain's cortex, were elavnegative, supporting the notion that they are glial in nature.

Using internally marked mosaics, we find that the pacemaker is located in brain but is not exclusive to the eyes, the ocelli, or the optic lobes, which is consistent with previous reports obtained in this and other insects of this class. Although the pacemaker may be a paired structure, we show that the functioning of one of them is sufficient for rhythmicity.

Finally, we report that glial expression is sufficient for some behavioral rhythmicity to be manifest. However, the rhyth-

\footnotetext{
Received Jan. 23, 1992; accepted Mar. 17, 1992.

We thank Kathleen K. Siwicki for providing anti-S anti-per antibody, Kalpana White and Steven N. Robinow for the anti-elav antibody, and Lawrence J. Zwiebe for the anti-Ecoper anti-per antibody. We are grateful to Xin Liu for the strain of transformant flies bearing the per- $\beta$-galactosidase fusion. We thank Verónica Cambiazo for assistance in mosaic scoring. We appreciate comments on parts of the manuscript from John S. Edwards, Karl-Friedrich Fischbach, and Steven N. Robinow. We thank John S. Edwards, Karl-Friedrich Fischbach, and Ian Meinertzhagen for their impressions concering the identity of per-expressing cells. We are grateful to the Department of Zoology at the University of Washington for the use of the confocal microscope (NIH Grant S10 RR04646). This work was supported by NIH Grant GM-33205.

Correspondence should be addressed to Jeffrey C. Hall, Biology Department, 235 Bassine Building, Brandeis University, 415 South Street, Waltham, MA 02254 9110 .

- Present address: Department of Zoology, NJ-15, Univcrsity of Washington, Seattle, WA 98195

Copyright (C) 1992 Society for Neuroscience $0270-6474 / 92 / 123321-29 \$ 05.00 / 0$
}

micities of animals for which per expression was confined to glia were weak, suggesting that neuronal per expression as well may be required for normal pacemaker function.

Circadian rhythms are endogenous ones with periodicities of approximately $24 \mathrm{hr}$. Little is known about the mechanism that generates these rhythms or, in most metazoans, where the pacemaker that drives them is located and how it is organized. In holometabolous insects in particular, nothing is known about the location of the oscillator, other than that it is not exclusive to the eyes or the optic lobes. Indeed, surgical lesion or ablation of these structures in Manduca (Truman, 1974), the housefly (Helfrich et al., 1985), and the mosquito (Kasai and Chiba, 1987) does not abolish rhythmicity. Likewise, adult Drosophila melanogaster bearing mutations that remove the eyes and/or the ocelli, eliminate photoreceptor function, or lead to greatly reduced optic lobes, express essentially normal locomotor activity rhythms (Helfrich and Engelmann, 1983; Helfrich, 1986; Dushay et al., 1989). In certain hemimetabolous insects, in contrast, the circadian pacemaker has been localized to the optic lobes (for review, see Chiba and Tomioka, 1987).

Mutations at the period (per) locus of $D$. melanogaster lengthen, shorten, or apparently abolish the circa $24 \mathrm{hr}$ rhythm of eclosion and locomotor activity of adult flies (Konopka and Benzer, 1971; for reviews, see Rosbash and Hall, 1989; Young et al., 1989; Hall, 1990). This and additional circumstantial evidence indicates that the product of the per gene is required for the expression of circadian rhythmicity. Moreover, there is direct evidence (Ewer et al., 1990) strongly suggesting that the per gene product is central to circadian pacemaker function itself.

Given this central role that the per gene product may play in pacemaker function, the location of cells expressing the per protein in the adult could be of heuristic value for determining the location of the circadian pacemaker in this holometabolous insect. In addition, the characterization of these cells might identify the types of cells that are involved in the generation of circadian rhythms.

The per protein is widely distributed in the adult, in both neuronal as well as non-neuronal tissues (Liu et al., 1988, 1991, 1992; Saez and Young, 1988; Siwicki et al., 1988). In addition, even within the CNS - which presumably houses the circadian pacemaker-per appears to be expressed in different cell types. Indeed, in the CNS, per-expressing cells occur both at locations at which glial cells have been described in insects, as well as in a small group of larger cells located in the cortex of the dorsal 
anterior brain, which have been hypothesized to be neurons ("lateral neurons," or LNs; Siwicki et al., 1988; Zerr et al., 1990). Thus, the determination of per's spatial expression in the adult fly has not (necessarily) resulted in the localization of the pacemaker. To do so requires determining where the presence of per product is sufficient and/or necessary for rhythmicity to be expressed. In $D$. melanogaster, such a question can be addressed through the use of genetic mosaics. Mosaics are composite organisms made up of normal and mutant tissue. By correlating the animal's phenotype with the location of wild-type tissue, the site at which wild-type gene function is sufficient and/or necessary for the expression of a wild-type phenotype can be inferred.

We report here the result of a mosaic analysis for the locomotor activity rhythm phenotype using internally marked per $^{+} \|$per $^{\prime}$ mosaics. We first provide a more detailed description than was previously available of the distribution of per-expressing cells in the CNS of adult $D$. melanogaster. In addition, we have initiated a characterization of the nature of these cells. To do so we have carried out double-label experiments using an antibody to the elav gene product, a putative neuron-specific nuclear antigen (Bier et al., 1988; Robinow and White, 1988, 1991). We report here experimental evidence that supports the previously proposed assignment of the various per-expressing cells to the glial and neuronal classes. Thus, we find that cells located at the borders between cortex and neuropil in the optic lobes and the central brain, as well as cells within neuropilar regions of the brain and lamina of the optic lobes, and a few smaller cortical cells in both the optic lobes and the central brain, do not express the elav gene product. This suggests that these cells are glial in nature. The same situation obtains in the thoracic and abdominal ganglia. In contrast, we found that the larger cortical per-immunoreactive cells, as well as a small group of previously identified cells located in the dorsalmost cortex of the central brain, coexpress the per and elav gene products, providing experimental support to their proposed neuronal identity.

The results obtained from our analyses of internally marked mosaics confirm and significantly extend the results obtained by Konopka et al. (1983) in an analysis of per ${ }^{+} \|$pers mosaics. Thus, as they reported, and consistent with the results of transplantation experiments (Handler and Konopka, 1979), we found that the focus for this gene's action mapped to the head. In the study by Konopka et al. (1983), the genotype of the internal tissue was not determined. Thus, a more precise localization of the gene's focus within the head was not possible. We now report that a patch of mutant tissue that included the ocelli, the eyes, and/or the optic lobes did not abolish rhythmicity, consistent with previous studies that made use of lesions, ablations, or mutations. Finally, we found that a very small patch of perexpressing tissue, which was essentially restricted to the subesophageal ganglion, was sufficient to confer rhythmicity. Since per-expressing cells in this region do not express elav, and are thus probably glia, this finding indicates that per expression in glial cells is sufficient for rhythmicity to be expressed. However, the rhythms of these animals were weak and of long period, suggesting that while glial expression may be sufficient for rhythmicity per se, it may not contain the entirety of the gene's focus for normal rhythmicities. In particular, few if any of the LNs were contained within these patches of wild-type tissue. Thus, per expression in these cells may indeed be required for normal rhythmicity to be manifest.

\section{Materials and Methods}

\section{Stocks}

The standard genetic variants used for this study are described in I indsley and Grell (1968) or Lindsley and Zimm (1990). The flies were raised at $25^{\circ} \mathrm{C}$ on a cornmeal, agar, molasses, yeast, and Tegosept medium, on a $12 \mathrm{hr}: 12 \mathrm{hr}$ light/dark (LD) cycle (lights on at 8 A.M.).

A preexisting germline transformant line bearing a fusion between a fragment of DNA from the per locus and the sequences encoding the bacterial enzyme $\beta$-galactosidase was used. The structure of this construct has previously been described (Liu et al., 1988). In transformants bearing this fusion (hereafter referred to as per- $\beta g a l), \beta$-galactosidase expression is a faithful reporter of per expression (Liu et al., 1988, 1991; see Results). In the transformant line used, the per- $\beta$ gal-containing P-element is located on a per-bearing $\mathrm{X}$ chromosome. Thus, in this line, the location of internally per ${ }^{+}$-expressing cells is revealed by virtue of their $\beta$-galactosidase expression. This chromosome was generated

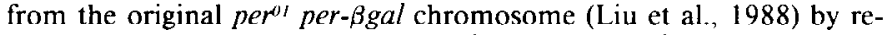
combination with a $\operatorname{per}^{+} w s n^{3}\left(w\right.$, white; $s n^{3}$, singed $)$ chromosome by one of us (M.J.H.-C.). It is hereafter referred to as per per- $\beta$ gal. By virtue of its construction, it is marked with $w$.

$\mathrm{per}^{+}$per- $\beta$ gal/per ${ }^{+}$flies were generated from a cross between a per ${ }^{+}$ per- $\beta$ gal male and Canton-S (per $)$ females. per $^{+}$controls flies were the (non-w) male progeny from this cross, while pertt controls were the (non-w) males obtained from an outcross between a per ${ }^{+}$per- $\beta g a l$ male and per $^{\prime \prime}$ females.

\section{Histochemistry}

All the histochemistry was done on frozen sections. Anesthetized flies were embedded and frozen in O.C.T. medium (Tissue-Tek, Miles), sectioned using an SLEE cryostat, and mounted on gelatin-coated slides. Flies were entrained to at least three $12 \mathrm{hr}: 12 \mathrm{hr}$ LD cycles prior to sectioning. For animals that had been in constant darkness (DD) for monitoring of "free-running" locomotor activity (see below), this reentrainment increases the intensity of per promoter-driven $\beta$-galactosidase expression (M. J. Hamblen-Coyle, unpublished observations) and immunohistochemical detcction of native per protcin (Zcrr ct al., 1990). In general, animals were sectioned between Zeitgeber time (ZT) 21 (i.e., $3 \mathrm{hr}$ before lights on) and ZT 4 ( $4 \mathrm{hr}$ after lights on). In wild-type flies, per immunoreactivity is highest at this time (Zerr et al., 1990), as is $\beta$-galactosidase activity in per $^{+}$per- $\beta$ gal transformants (Zwiebel et al., 1991).

$\beta$-Galactosidase histochemistry. $\beta$-Galactosidase histochemistry was zarried out on $15-\mu \mathrm{m}$-thick sections as described in Liu et al. (1988), using the chromogen $\mathrm{X}$-gal (5-bromo-4-chloro-3-indolyl- $\beta$-D-galactojyranoside; Boehringer Mannheim Biochemicals).

Immunohistochemistry. Anti-per, anti- $\beta$-galactosidase, and anti-elar solyclonal antibodies were used for immunohistochemistry. Two diferent anti-per antibodies were used. The first, referred to as anti-S, was enerated in rabbit against a synthetic peptide corresponding to a sequence located ncar the sitc of the per's mutation (Siwicki et al., 1988). The second, here called anti-Ecoper, was raised in rat against an incomplete per protein synthesized in Escherichia coli (cf. Liu et al., 1991, 1992). Both anti-per antibodies produce qualitatively identical patterns of staining when used on wild-type flies. Quantitatively, however, the anti-Ecoper produces a more intense signal. The antibody to $\beta$-galactosidase was a rabbit antibody purchased from Cappel (a subsidiary of Organon Teknika Corporation, Durham, NC). The anti-elav antibody was raised in rat (Robinow and White, 1991).

All immunohistochemistry was carried out on 6-10 $\mu \mathrm{m}$ frozen sections. Sections stained using biotinylated secondary antibodies and avidin-biotin-peroxidase (Vectastain ABC kit, Vector Labs, CA) were treated as described in Siwicki et al. (1988) with only minor modifications. For immunohistochemistry involving fluorescent antibodies, sections were treated as described in Siwicki et al. (1988) through the application of the relevant biotinylated secondary antibody. Following this step, sections were rinsed in phosphate-buffered saline (PBS; $\mathrm{pH}$ 7.2) plus $0.1 \%$ Triton $X-100$ (PBST) for $5 \times 10 \mathrm{~min}$, at room temperature. Fluorochrome-conjugated avidin (Texas Red or fluorescein DCS, Vector Labs) was then applied at a dilution of 1:200 for $1 \mathrm{hr}$, at room temperature. Then, sections either were rinsed $3 \times 10 \mathrm{~min}$ in PBST and $2 \times 10 \mathrm{~min}$ in PBS and then mounted in glycerol, or, if double labels were to be done, were rinsed $5 \times 10 \mathrm{~min}$ in PBST, after which the procedure used for the first primary antibody was repeated for the second one. In some experiments involving the anti-elav antibody, a 
directly conjugated rhodamine (RITC) anti-rat antibody was used (Sigma), at a dilution of 1:200.

Primary antibodies were applied at the following dilutions: anti-S antibody, 1:50; anti-Ecoper, 1:200; anti- $\beta$-galactosidase, 1:4000; antielav, 1:50.

To avoid cross-reactivity of secondary antibodies, double-label experiments using anti-per and anti-elav (rat) antibodies were carried out using the anti-S antibody (rabbit), whereas for those involving anti-per and anti- $\beta$-galactosidase (rabbit) antibodies, the anti-Ecoper (rat) antibody was used.

Fluorescently stained sections were viewed under normal fluorescence as well as confocal (Bio-Rad confocal imaging system) microscopy. In the latter, the aperture was set to produce the minimal depth of field $(0.6 \mu \mathrm{m})$. In order to confirm that colocalization was not an artifact due to the wider absorption spectrum of the fluorescein, the two fluorochromes used to visualize different antigens were reversed.

Controls. Controls for specificity of staining were (1) experiments in which the primary antibody was omitted $(n=3-6$ flies, depending on the antibody used, in at least two separate experiments) and (2) experiments involving sections of flies lacking the relevant epitope. These were (1) per" flies $(n=18)$, for the anti-S antibody-per" flies carry a non-sense mutation upstream of the sequence that encodes the $S$ peptide (Yu et al., 1987); (2) per flies, for the anti-Ecoper antibody $(n=6)-$ these flies were $D f(1) T E M 202 / D f(1) 64 j 4$ trans-heterozygotes, which are viable, behaviorally arrhythmic (Smith and Konopka, 1981; Hamblen et al., 1986), and molecularly per (Bargiello and Young, 1984; Reddy et al., 1984); and (3) per ${ }^{+}$flies ( $n=6$, in three separate experiments) for anti- $\beta$-galactosidase. In addition, for double-label experiments, crossreactivity of an anti-rat (rabbit) secondary antibody to a primary antibody of rabbit (rat) origin was determined using the anti-rat (rabbit) secondary antibody in conjunction with the relevant rabbit (rat) primary antibody ( $n=3-6$, depending on the antibody used, in at least two separate experiments). None of these controls showed any localized staining.

\section{Generation of mosaic animals}

Gynandromorph mosaics were produced by making use of the second chromosome mutation paternal loss (pal; Baker, 1975). When homozygous in males, this mutation can induce the somatic loss (as well as the loss prior to the first zygotic division) of any paternally inherited chromosome (Baker, 1975). Three types of mosaics were produced. In the first ("test" mosaics), somatic loss of a patcrnal pert per- $\beta$ gal X chromosome uncovered a patch of genotypically per"' tissue in an otherwise $\mathrm{per}^{+}$per-Bgal/per"t animal. These gynandromorphs were recov-

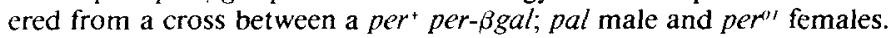
In the second ("control" mosaics), the mother carried the wild-type per allele. In this case, somatic loss of the paternal $X$ chromosome resulted

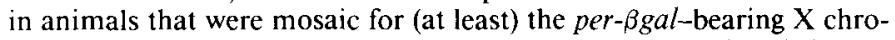
mosome (see below), but which were genotypically per ${ }^{+}$in all tissues. They were generated to control for the effects that somatic loss of this chromosome per se might have on an animal's rhythmicity. Finally, mosaics that were also per ${ }^{+}$in all tissues but that did not carry the fusion gene were generated. These internally unmarked "all per" " mosaics were made to control for the effects of mosaicism on rhythmicity that could not be due to mosaicism of per- $\beta$ gal expression. They were recovered from a cross between a per ${ }^{+}$;pal male (which also carried the mutation vellow that was present in the stock) and per females. In all three cases, the females' $X$ chromosomes carried the recessive eye color mutation chocolate (cho) and the bristle mutation $s n^{3}$ in addition to the relevant per allele. Thus, mosaic animals were identified by the presence of patches of cho- and/or $s n^{3}$-marked external tissue. Internally, per-expressing tissue that had lost the paternal per ${ }^{+}$per- $\beta$ gal $\mathrm{X}$ chromosome would be identified by the lack of histochemically detected $\beta$-galactosidase activity. In test mosaics, these tissues would be genotypically per $^{\circ}$. In some cases the males (but not the females) also carried the fourth chromosome mutation sparkling-poliert, which was present in the original pal stock. Crosses were made using a single male and four or five virgin females. To maximize the number of progeny obtained, parents were transferred onto fresh food every 3-4 d, three or four times. In most of these crosses, mosaic animals were recovered at a frequency of $1-3 \%$.

Nonmosaic pert per- $\beta$ gal/per" flies were generated from a cross between a per ${ }^{\prime l}$ cho $s n^{3}$ male and per' per- $\beta g a l$ females. In addition, ex-

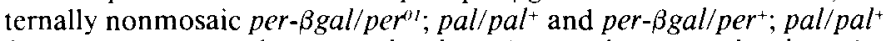
females, and perol cho $s n^{3} ;$ pal/pal ${ }^{+}$and $p e r^{+}$cho $s n^{3}$; pal/pal' males were collected. They were derived from the progeny of the relevant mosaic-generating cross.

In order to control for the effects that heterozygosity for the pal mutation per se might have on a fly's rhythm, generated (nonmosaic) $\mathrm{per}^{+}$per- $\beta \mathrm{gal} / \mathrm{per}^{+}$animals for which the pal-bearing chromosome was derived either from a homozygous pal father or from a heterozygous palipal mother. If the phenotype of a pal-bearing fly were due to heterozygosity for pal per se, such a phenotype should be found among the offspring of either parent. In contrast, if it were due to the effects of pal on chromosome segregation, that phenotype would presumably be found only among the progeny derived from the $\mathrm{pal}$-bearing father. A caveat to this interpretation is that the effects of this mutation on the progeny of pal-bearing mothers has not been extensively characterized.

The pal mutation can induce the loss of any chromosome (Baker, 1975). However, of the autosomes, only loss of the fourth chromosome is compatible with viability. In addition, both the $X$ and the fourth chromosomes can be lost simultaneously. Thus, it is possible that some of the mosaic animals that were tested were mosaic for the fourth in addition to the $X$ chromosome. In order to examine the effects that the pal-induced loss of the fourth chromosome might have on a fly's rhythm phenotype, flies (completely) hemizygous for this autosome were generated. Hemizygosity for the fourth chromosome gives rise to a Minute phenotype, as a result of the presence of a Minute $[M ; M(4)]$, locus on this chromosome. Thus, animals that had only one copy of this autosome could be identified as the phenotypically Minute progeny (Morata and Ripoll, 1975) from a cross between a male bearing attached-4th chromosomes [C(4)RM marked with the wing mutation cubitus interruptus and the eye mutation eyeless $\left.\left(e y^{k}\right)\right]$ and per $^{+}$cho $s n^{s}$ females.

$p^{\prime} r^{\prime}$ and per $^{\circ /}$ control flies were the males obtained from an outcross between a Canton-S male and per cho $s n^{3}$ and per ${ }^{\prime \prime}$ cho $s n^{3}$ females, respectively.

\section{Scoring of per mosaics}

Upon collection of a mosaic animal, a rough description was usually made, indicating which regions of the animal were (externally) mutant. After testing, sectioning, and staining, the animal's identity was confirmed by examining whether the distribution of externally mutant tissue and that of the X-gal stain was consistent with the original description. The animal's head, thorax, and abdomen was then given a score, depending on the extent to which its tissues expressed $\beta$-galactosidase relative to that seen in nonmosaic animals: 1 if it was not detectably mosaic, 0.5 if it was mosaic, and zero if it was apparently entirely null. For the head, scores of 0.1 and 0.9 were given to animals that had a very small or a very large patch of mutant tissue, respectively.

A more detailed description of the internal mosaicism of the head was then obtained. To do so, we indicated whether a given structure had a mutant patch (large patch if more than $\sim 70 \%$ of the cells that are normally stained were null), or was entirely null, on one or both sides. The structures considered were ocelli, eyes, central brain, and optic lobes. For the latter, the lamina, medulla, lobula and lobula plate, and a small cluster of cells located in the second optic chiasm were scored separately. These structures (except for the ocelli) are indicated in Figure 10.

The staining of a few exceptional animals of interest was further characterized more quantitatively. To do so, the number of eclls stained in a given structure or region was counted for each section and quantified relative to that seen in normal (nonmosaic) animals. See Results and Figure 10 for a description of the areas that were scored.

\section{Analysis of circadian rhythms}

Locomotor activity of individual adult flies was monitored as described in Hamblen et al. (1986). Locomotor activity rhythm phenutypes in DD were characterized by inspection of actograms and by performing $\chi^{2}$ periodogram analyses (as described in Hamblen et al., 1986; cf. Sokolove and Bushnell, 1978). Prior to the periodogram analysis, the data were filtered using a 4-hr-cutoff low-pass filter, described in Dowse and Ringo (1989). This filtering of the data increases the sensitivity of the periodogram analysis (data not shown; cf. Dowse and Ringo, 1989).

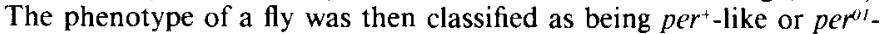
like based on the amplitude and width of the peak of its periodogram relative to those seen in the $\mathrm{per}^{+}$and $\mathrm{per}^{\circ t}$ controls. The amplitude, also called "power" (Liu et al., 1991), refers to the height of the peak above the 5\% significance line (cf. Hamblen et al., 1986); the width is the 


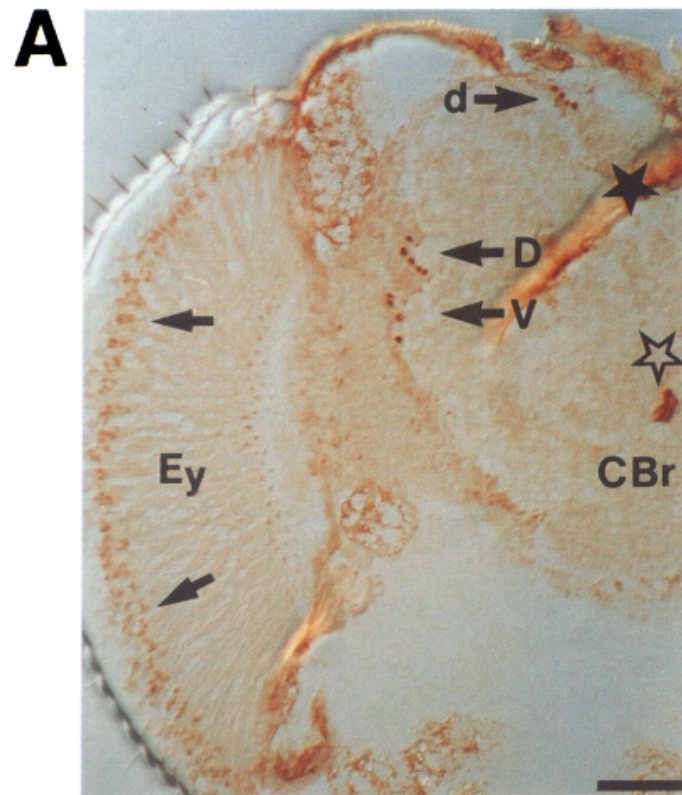

B

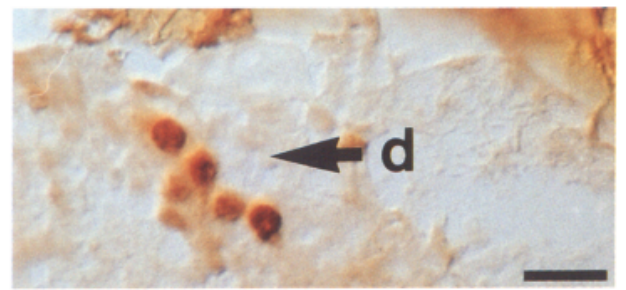

C

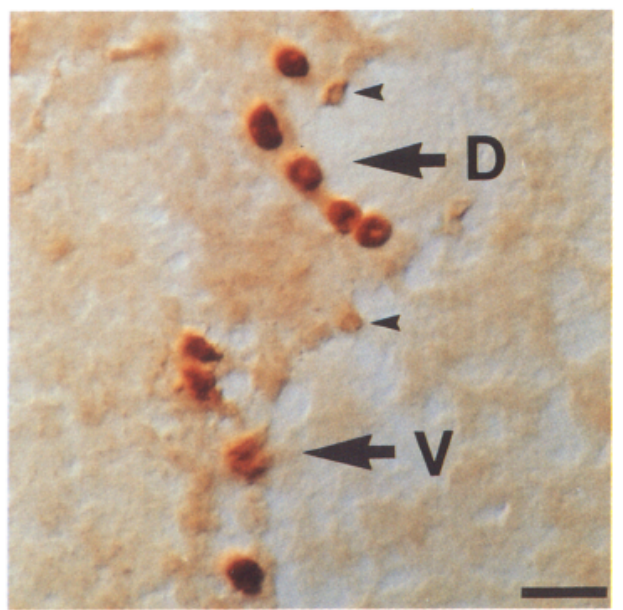

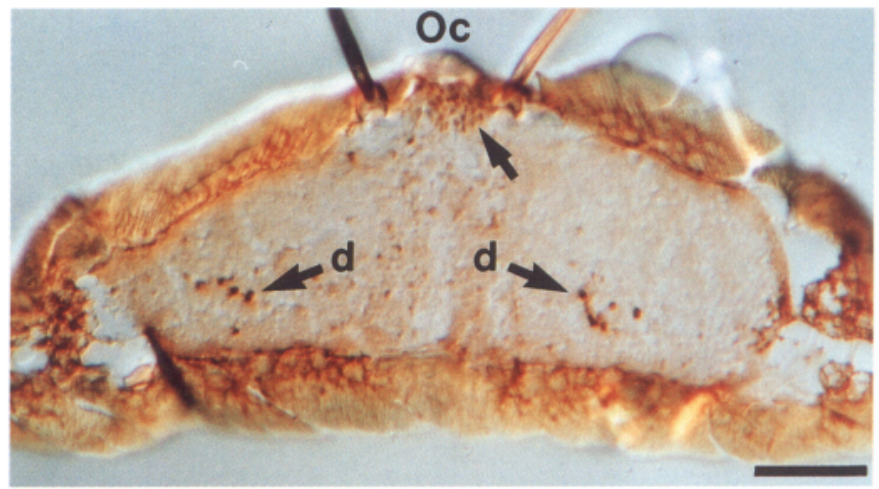

D
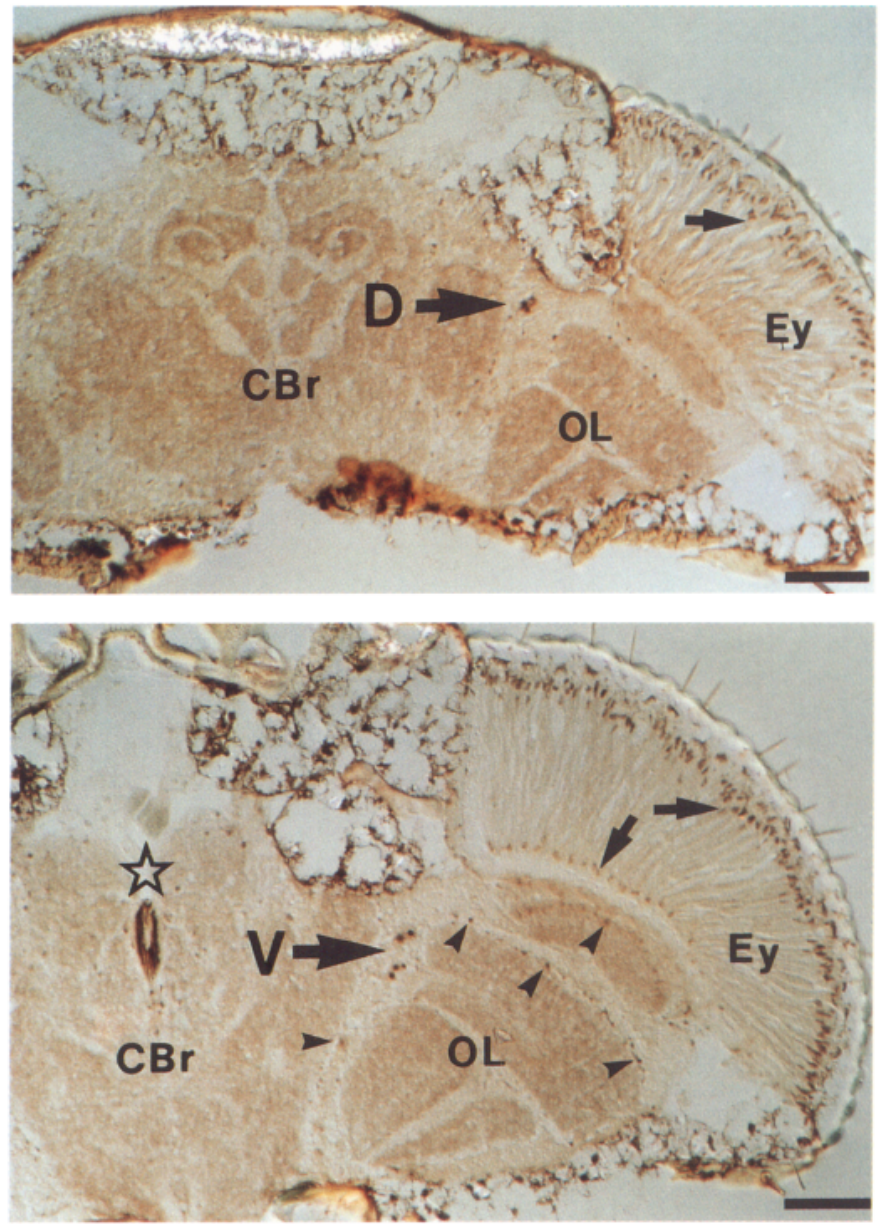

Figure 1. Distribution of per immunoreactivity in the brain of wild-type flies, visualized using the anti-Ecoper $(A-D)$ or the anti-S antibody $(E-$ $F$. $A$, Distribution of per immunoreactivity in a frontal section of a wild-type fly. Note the occurrence of a dorsalmost cluster $(d)$, and that of the more ventral group of dorsal $(D)$ and ventral $(V)$ LCs. Unlabeled arrows point to photoreceptor nuclei. Solid star, piece of cuticle. Scale bar, 50 $\mu \mathrm{m} . B$ and $C$, Higher-magnification views of $A(B$, dorsal; $C$, more ventral). Arrowheads, per-immunoreactive cells occurring at the margins of the cortex of the central brain. Scale bars, $10 \mu \mathrm{m}$. $D$, Horizontal section through the dorsalmost region of the head showing the per-immunoreactive cells in the cortex of the central brain $(d)$. The unlabeled arrow points to the photoreceptor nuclei of the ocelli $(O c)$. Scale bar, $50 \mu \mathrm{m}$. $E$ and $F$, Sections showing per immunoreactivity on horizontal sections of wild-type flies ( $E$, dorsal; $F$, more ventral). Note the conspicuous staining in the dorsal $(E$, labeled $D)$ and ventral $(F$, labeled $V$ ) LCs. In addition, per-specific labeling occurred in the nuclei of the photoreceptors of the eye (unlabeled arrows in $E$ and $F$ ), at the margins of the cortex and the neuropil in the optic lobes and the central brain $(F$, arrowheads), and within the neuropil of the lamina $(F$, arrowhead $)$. Scale bars, $50 \mu \mathrm{m}$. Other abbreviations: $C B r$, central brain; $E y$, eye; $O c, O c e l l i ; O L$, optic lobes. $O p e n$ star, esophagus.

number of period values (in $0.5 \mathrm{hr}$ increments) within a peak that were statistically significant (see Results).

\section{Mapping the focus of per's action: data analysis}

To aid in the mapping of the focus of the action of the per gene, a database was constructed. This contained a description of each animal's spatial pattern of per expression as well as a summary of its locomotor activity rhythm phenotype. The pattern of per expression was summarized by entering the "staining score" for the head, thorax, and abdomen (see above), and by indicating the presence of a mutant patch or of an entirely mutant structure, on one or both sides of the animal, for each structure considered (see above, and Fig. 10). The summary of an animal's locomotor activity rhythm phenotype included the main 
periodicity present in the animal's locomotor activity record, its amplitude and width (see above), as well as a verdict as to whether these values corresponded to per $^{+}$-like or per $^{\circ t}$-like rhythmicities.

This database was constructed and administered by the program EXCEL (Microsoft). By performing sorting and extraction operations on it, a search could be made for all those animals whose rhythm or staining phenotype met particular criteria (e.g., a listing of all arrhythmic animals, or of those animals that had a large mutant patch in a given structure and were rhythmic, etc.). This proved to be an efficient way of storing the large amount of information that was collected, and allowed particular staining patterns, rhythm phenotypes, and statistics to be rapidly obtainable from these data.

\section{Results}

Distribution and nature of per-expressing cells in the CNS of adult $D$. melanogaster

\section{Distribution of per-expressing cells in the brain of adult $\mathrm{D}$.} melanogaster

We have used wild-type $\left(\right.$ per $\left.^{+}\right)$and $p e r^{+}$per-Bgal-bearing transformants to determine the distribution of per-expressing cells in the brain of adult $D$. melanogaster. Our findings are consistent with the broad descriptions reported by Siwicki et al. (1988), Liu et al. (1988, 1991), and Zerr et al. (1990). Thus, we found that per-expressing cells occurred in the ocelli, in the photoreceptors of the eyes, and throughout the central brain and the optic ganglia (Figs. 1, 2).

In wild-type flies, the most conspicuously per-immunoreactive cells occur in the cortical area located between the inner margin of the medulla and the central brain neuropil (Fig. 1; Siwicki et al., 1988; Zerr et al., 1990). These lateral cells (LCs) are also the largest per-immunoreactive cells in the fly's brain (their total diameters ranged from 10 to $12 \mu \mathrm{m}$ ). Based on their position, these cells might correspond to medulla tangential neurons (Fischbach and Dittrich, 1989; K.-F. Fischbach, personal communication). The LCs were routinely stained in animals sectioned during the early portion of the day; indeed, they were observed in $84 \%$ (69 of 82 ) of the flies stained during the peak of immunoreactivity. We do not know why they were not seen in the remaining preparations. This was not due to their being masked by a high background staining. It could have been that these individuals were "off peak," with regard to the cycling of immunoreactivity (for which fairly steep rises and falls have been observed; Zerr et al., 1990).
The LCs are restricted to the supracsophageal ganglion, and are distributed in two separate clusters (Fig. 1). A first one is located at a depth of $80-100 \mu \mathrm{m}$ (where $0 \mu \mathrm{m}$ corresponds to the dorsal surface of the brain, with reference to horizontal sectioning), slightly anterior to the region of the central brain directly opposite to the inner margin of the medulla (" $D$ " in Fig. $1 A, C, E)$. At this more dorsal location, a rather compact cluster of three to seven $(4.5 \pm 0.2$, mean $\pm \mathrm{SEM} ; n=40)$ of such per-immunoreactive cells were counted on each side of the brain, distributed over a depth of $\sim 20 \mu \mathrm{m}$. The second group of LCs occurs at the height of the esophagus, at a depth of 140 $160 \mu \mathrm{m}$. Here, four to seven LCs $(5.7 \pm 0.3 ; n=42)$ were counted, distributed over a depth of $20-30 \mu \mathrm{m}$. In contrast to those in the first cluster, these cells tended to occur in a line that spanned the cortical area between the central brain and the inner border of the medulla ("V" in Fig. $1 A, C, F$ ). Thus, the two groups of LCs are separated by $20-30 \mu \mathrm{m}$ that are devoid of such cells. Whether these two groups belong to the same functional class is unknown. In their study of the cycling of per immunoreactivity, Zerr et al. (1990) scored the staining intensities of the LCs, treating all such cells as a single group $(\mathrm{K} . \mathrm{K}$. Siwicki, personal communication). The LCs are the main or only large cells found at the locations described above, and are thus potentially identifiable even in unstained preparations (see Fig. $2 C, D, E)$.

In addition to the LCs, per-immunoreactive cells were also found within other cortical areas. A group of such cells, located in the posterior, dorsalmost cortex (at a depth of 25-50 $\mu \mathrm{m}$ ), has been noted previously (Siwicki et al., 1988; "d" in Fig. $1 A, B, D)$. These cells are smaller (size, 4-6 $\mu \mathrm{m}$ ), and their staining is more variable. Thus, they were seen in only 18 of 28 preparations $(\sim 65 \%)$. In these preparations, between 2 and 10 such cells could be found on either side of the brain. The relatively small percentage of preparations that showed staining in these cells could in part be due to a lower level of per expression in these cells, as this antibody is known not to be a very sensitive one (Ewer el al., 1990; Zerr et al., 1990). The characterization of these cells is further complicated by their position: being so dorsal, sections containing them are frequently lost, or exhibit poor morphology, in horizontally sectioned preparations.

In addition, numerous per-expressing cells occurred throughout the central brain and the optic ganglia (Fig. 1). These in-

Figure 2. $A-J$ are confocal images of anti- $\beta$-galactosidase (green) and anti-elav (red) immunoreactivity of horizontal sections of per $^{+}$per- $\beta$ gal/per ${ }^{+}$flies. Arrows point to cells that coexpress both antigens; arrowheads point to cells that are only $\beta$-galactosidase immunoreactive. $K$ shows confocal images of anti-per (anti-S antibody; green) plus anti-elav (red) staining of horizontal sections of per ${ }^{+}$flies. Arrows point to cells that coexpress both antigens; the arrowhead points to a cell that is only per immunoreactive. The single-color panels show the pattern of immunoreactivity obtained for each of the two antibodies separately. $A$, Section through the dorsalmost central brain. Note the presence of an clavpositive and $\beta$-galactosidase-positive cell. Scale bar, $16.7 \mu \mathrm{m}$. $B$, Higher-magnification view of $A$. Scale bar, $8 \mu \mathrm{m}$. $C$, Low-magnification view showing colocalization of $\beta$-galactosidase and elav immunoreactivity in LCs, and only $\beta$-galactosidase immunoreactivity in per-expressing cells located at the borders of the cortex and the neuropil of the optic lobes and the central brain, in the inner chiasm, and within the neuropil of the lamina and the central brain. Scale bar, $20 \mu \mathrm{m}$. D. Section showing colocalization of $\beta$-galactosidase and elav immunoreactivity in the more dorsal LCs, and only $\beta$-galactosidase immunoreactivity in per-expressing cells located at the borders of the cortex and the neuropil of the optic lobes and the central brain. Scale bar, $16.7 \mu \mathrm{m}$. E. Section showing colocalization of $\beta$-galactosidase and elav immunoreactivity in the more ventral LCs, and only $\beta$-galactosidase immunoreactivity in per-expressing cells located at the borders of the cortex and the neuropil of the optic lobes and the central brain, as well as in a single cell within the cortex. Scale bar, $10 \mu \mathrm{m}$. $F$, Section illustrating the colocalization of $\beta$-galactosidase and elav immunoreactivity in the photoreceptors of the ocelli. Scale bar, $20 \mu \mathrm{m}$. $G$, Section illustrating the colocalization of $\beta$-galactosidase and elav immunoreactivity in the photoreceptors of the eye. Scale bar, $20 \mu \mathrm{m}$. $H$. Section showing the occurrence of only $\beta$-galactosidase-immunoreactive per-expressing cells in the inner chiasm, at the border of the cortex and the neuropil, and within the cortex of the lobula plate. Scale bar, $16.7 \mu \mathrm{m} . I$, Section showing the occurrence of only $\beta$-galactosidase-immunoreactive per-expressing cells at the borders of cortex and neuropil, as well as within the cortex and the neuropil of the central brain. Scale bar, $16.7 \mu \mathrm{m}$. $J$. Section showing the occurrence of only $\beta$-galactosidase-immunoreactive per-expressing cells at the borders of cortex and neuropil, as well as within the cortex and the neuropil of a thoracic ganglion. Scale bar, $16.7 \mu \mathrm{m}$. $K$, Section showing colocalization of per and elav immunoreactivity in a dorsal LC, and only per immunoreactivity in a cell located at the border of the cortex and the neuropil of the medulla optic lobe. Scale bar, $7 \mu \mathrm{m}$. $E y$, eye; $L a$, lamina; $M e$, medulla; $L o$, lobula; $L p$, lobula plate; $I c$, inner chiasm; $C B r$, central brain; $T h$, thorax. 

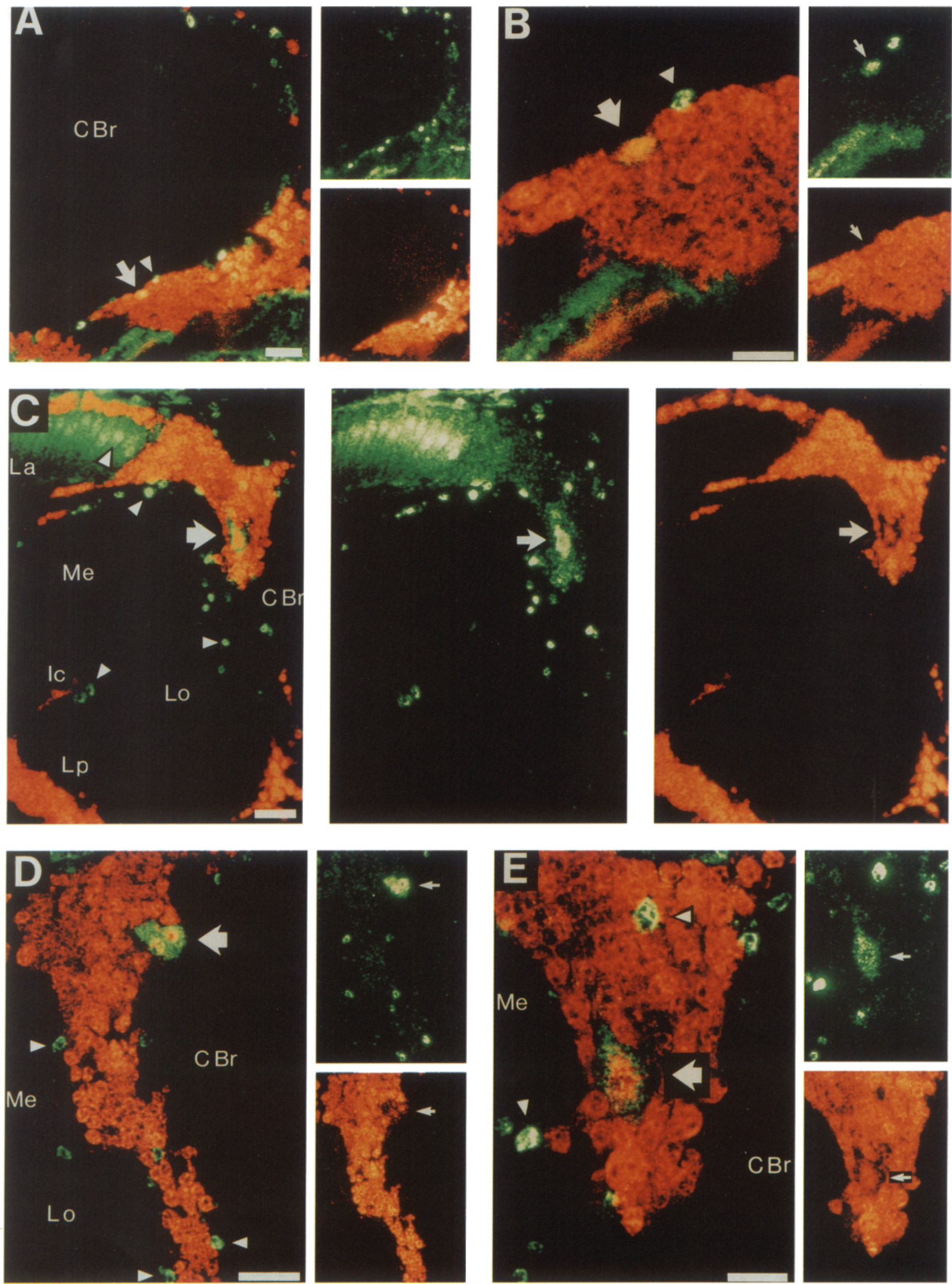

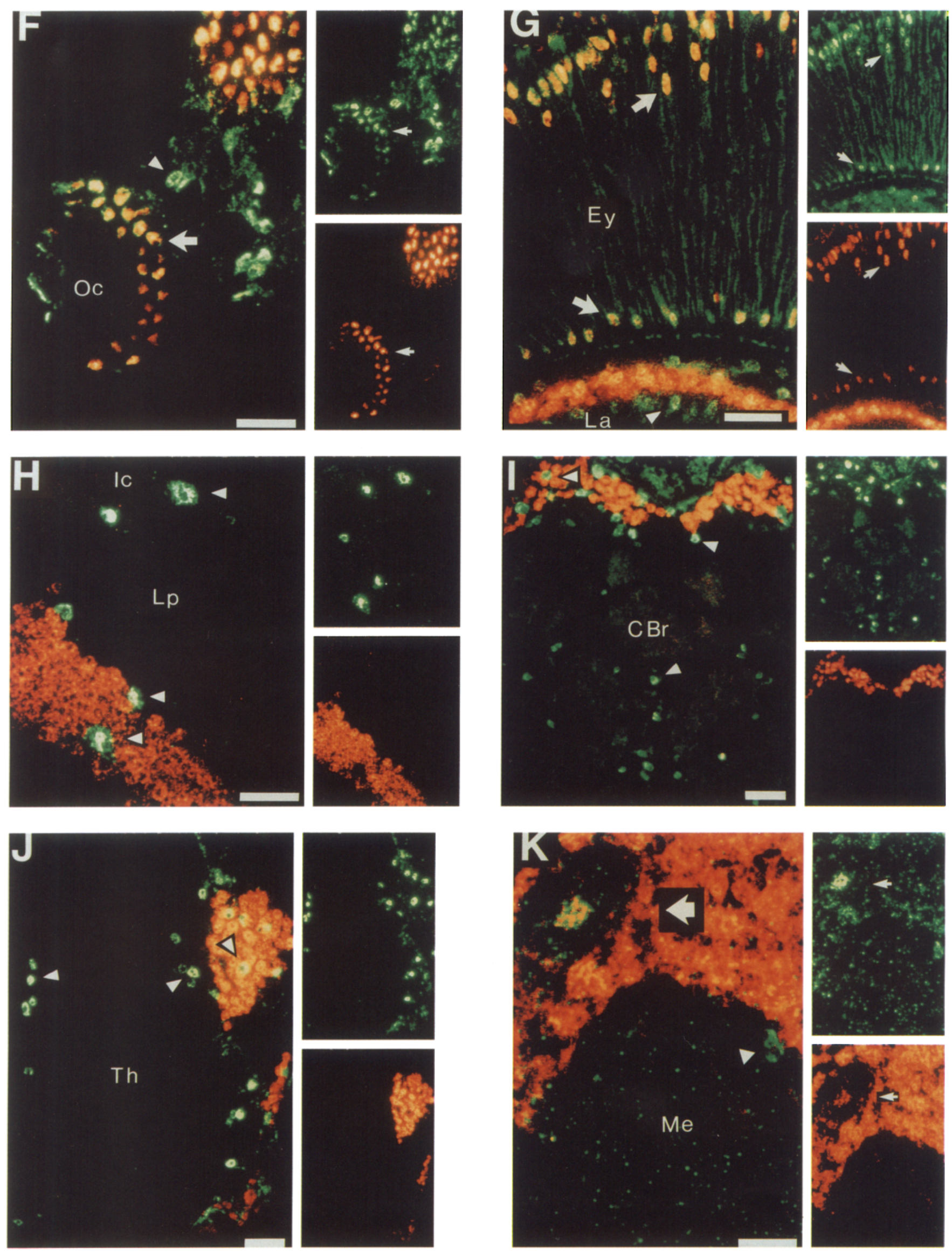
cluded cells located at the borders between cortex and neuropil of the central brain and the optic lobes, cells within the neuropil of both the central brain and the lamina, a small cluster of cells located within the inner chiasm, as well as cells that occurred within the cortex of the central brain, and optic lobes (not shown; compare Fig. $2 I, E, H)$. In contrast to the LCs and the dorsalmost cortical per-expressing cells, which are restricted to the supraesophageal ganglion, the distribution of these cells is not limited to particular levels within the brain (e.g., moving in a dorsal to ventral, as the flies were sectioned). Instead, they occurred throughout the entirety of the head's nervous system, at the locations summarized above.

The distribution of $\beta$-galactosidase-immunoreactive cells in heads of per $^{+}$per- $\beta$ gal-bearing transformants was qualitatively identical to the one described above for per-immunoreactive cells in wild-type flies. Indeed, as shown in Figure $2, \beta$-galactosidase-expressing cells that were morphologically similar to per-immunoreactive ones could be found at all the locations described above. Quantitatively, however, a much larger number of cells were stained in the central brain and the optic lobes. In addition, the staining of most of these cells was more intense. Exceptions to this were the LCs and the dorsalmost cortical cells. In contrast to what was obtained in per $^{+}$flies, their staining was comparatively fainter than that of neighboring cells, thus making them more difficult to visualize in the reporter-bearing transformant (see below).

We believe that the differences between the pattern of $\beta$-galactosidase immunoreactivity seen in the transformants and that of per-immunoreactive cells in wild-type flies are quantitative rather than qualitative ones, and are due to differences between the levels of $\beta$-galactosidase expression in the transformants and those of per in wild-type flies. They are probably due in part to the relatively high stability of $\beta$-galactosidase, as has been noted in the case of other gene fusions that use this reporter enzyme (e.g., Doe et al., 1988), and not solely to a higher affinity of the anti- $\beta$-galactosidase antibody. Indeed, when the expression of the fusion gene was monitored using the anti-S antibody (in a per $^{\text {It }}$ genetic background), a larger number of cells were stained than when this same antibody was used to stain the per product in wild-type flies (not shown). This antibody recognizes the product of the fusion gene because the fragment of DNA contained in this fusion includes the sequences coding for the epitope against which the anti-S antibody was generated (Siwicki et al., 1988).

In order to test directly whether the expression of the fusion gene was a faithful reporter of per expression, we asked whether per and $\beta$-galactosidase immunoreactivities were colocalized in sections of per $^{+}$per- $\beta$ gal flies (involving six animals, from two separate experiments). As shown in Figure 3, in no case were we able to find per-immunoreactive cells that were unambiguously $\beta$-galactosidase negative. As expected, however, per-immunoreactivity (per se) was comparatively stronger than that of $\beta$-galactosidase in the LCs, whereas the opposite was obtained at other locations. Thus, we conclude that the expression of the per- $\beta$ gal fusion gene does accurately reflect the pattern of per expression seen in wild-type flies, and that the differences between the patterns of staining obtained for the two antigens are quantitative ones. Interestingly, the intracellular distribution of the reporter gene's product seemed to be somewhat broader than that of per immunoreactivity. Thus, whereas the per product appeared to be predominantly nuclear (cf. Liu et al., 1992), that of the fusion gene was detected in both the nucleus and the cytoplasm. Because of their larger cytoplasm, this was most evident in the LCs. This broader distribution of the fusion protein could also be due to its enhanced detectability owing to its greater abundance.

In addition to this immunohistochemical evidence, other evidence suggests that the expression of the fusion gene faithfully reflects the normal pattern of per expression. Thus, if the fragment of per DNA that mediates the expression of $\beta$-galactosidase in per- $\beta$ gal-bearing transformants drives instead the expression of a complete per gene in transformants, it rescues the arrhythmicity of a per ${ }^{\prime \prime}$ host: nearly every individual is rhythmic and exhibits near-normal periodicities (Citri et al., 1987; Yu et al., 1987; Ewer et al., 1990) as well as temperature compensation (Ewer et al., 1990). Likewise, the temporal and spatial pattern of per-driven $\beta$-galactosidase expression in per- $\beta$ gal-bearing transformants is similar to that of the per gene throughout development (Liu et al., 1988).

\section{Nature of per-expressing cells}

The identity of the cells of the fly's nervous system that express per is unknown, other than that of the cells in the eye, which has been experimentally proven to be photoreceptor cells (Zerr et al., 1990; see below). per-expressing cells in the optic ganglia and the central brain were classificd by Siwicki ct al. (1988) as (putative) neurons and (putative) glia based on their position. Thus, the LCs were baptized lateral neurons. In contrast, the cells found at the border between cortex and neuropil (e.g., in the optic lobes; compare Fig. 1) were considered to be glial cells. A class of glia has indeed been described at this position in Diptera (Musca: interface glia; Strausfeld, 1976). Likewise, the cells that are located within the neuropil (e.g., in the central brain; compare Fig. 1) could correspond to neuropilar glia (Strausfeld, 1976). Finally, the cells within the lamina (compare Fig. 1) could be the epithelial glia (Liu et al., 1988) that have been described in Musca (Campos-Ortega and Strausfeld, 1973; Saint-Marie and Carlson, 1983).

These assignments are unsatisfactory as they are only based on the cells' positions. One way to investigate the identity of per-expressing cells is to examine whether they also express previously characterized antigens. Given the putative glial nature of at least some of these cells (see above), we sought an antigen that would be restricted either to glia or to neurons. Of these, the most useful at present is the product of the elav gene. Indeed, a growing body of evidence has revealed that, throughout development, this gene is only expressed in neurons, and occurs in all identifiable classes of neurons (Bier et al., 1988; Robinow and White, 1988, 1991). Thus, the product of the elav gene is a good candidate for a neuron-specific marker. The antielav antibody that we have used is a more useful reagent for our purposes than anti-HRP, another neuronal marker (Jan and Jan, 1982). Indeed, in contrast to the latter, which labels neuronal membranes-most conspicuously, in processes-the anti-elav antibody identifies a nuclear antigen (near where per is expressed subcellularly, cf. Liu et al., 1992). In addition, the anti-elav antibody has, so far, not labeled non-neuronal cells (Robinow and White, 1991). This is not the case for the anti-HRP antibody (Jan and Jan, 1982).

We carried out double-label experiments using anti- $\beta$-galactosidase and anti-elav antibodies on per $^{\dagger}$ per- $\beta$ gal-bearing transformants. For this experiment we used mostly this transformant (28 flies of this genotype were sectioned, in five separate experiments, all of which led to good, rather invariant signals). In 

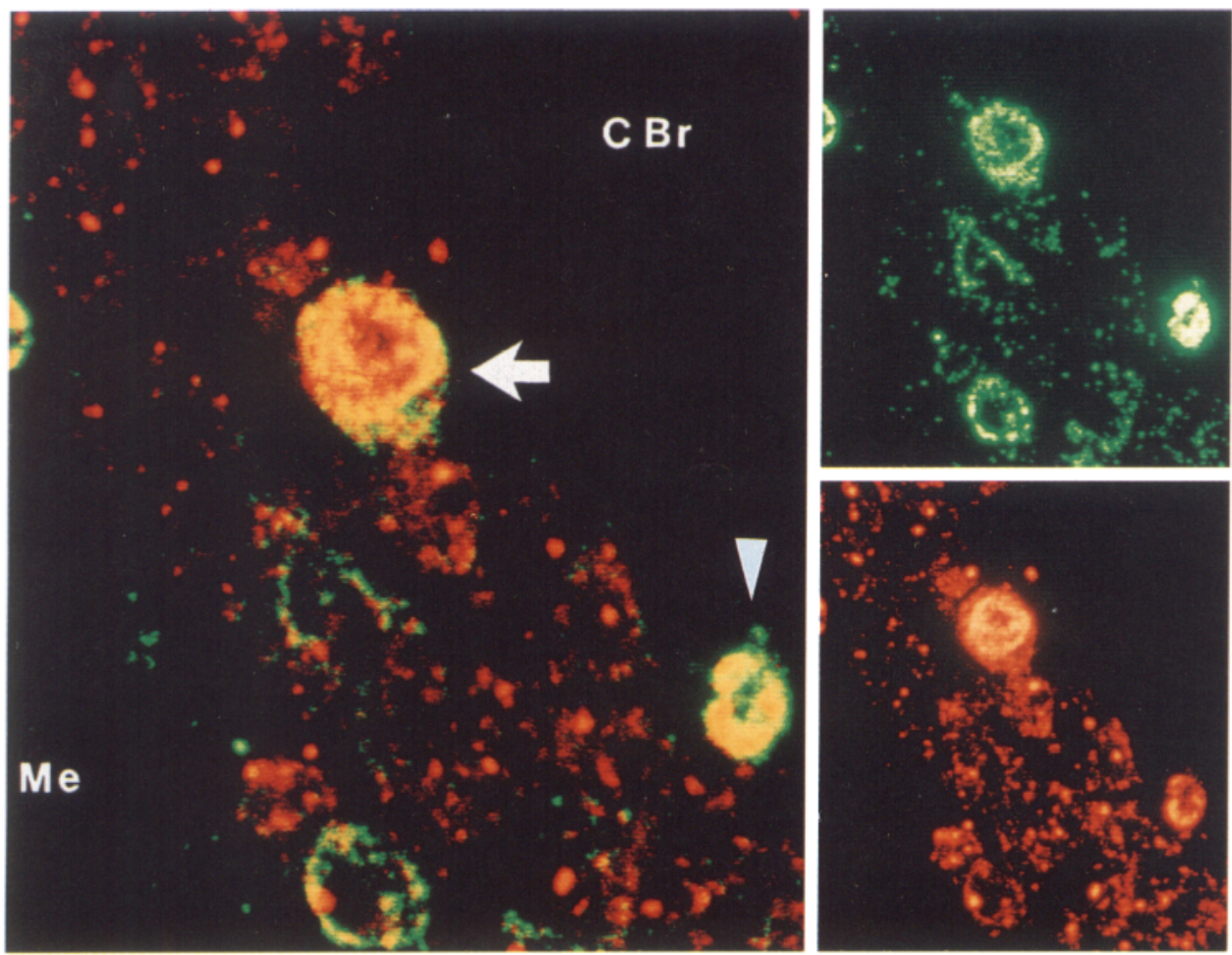

Figure 3. Confocal image of anti$\beta$-galactosidase (green) and anti-per (anti-Ecoper antibody; red) immunoreactivity on horizontal sections of $\mathrm{per}^{+}$per- $\beta \mathrm{gal} / \mathrm{per}^{+}$transformant. Note that all per-immunoreactive cells are also $\beta$-galactosidase positive. However, the dorsal LC (arrow) appears to be more intensely per immunoreactive than $\beta$-galactosidase immunoreactive, whereas the reverse obtains for the cells located at the margins of cortex and neuropil (e.g., arrowhead). $\mathrm{Me}$, medulla; $\mathrm{CBr}$, central brain. Magnification, $120 \times$.

per $^{+}$flies ( $n=6$, from two separate experiments, involving anti-S and anti-elav), the staining had a higher background and was less robust and reproducible than that using the transformant. Nevertheless, the results obtained in both preparations were qualitatively the same (see below).

Results of such experiments are shown in Figure 2. They show that the $\beta$-galactosidase-immunoreactive cells in the ocelli (Fig. $2 F$ ) and the eyes (Fig. 2G) were elav positive. Thus, per-expressing cells in both the eyes (cf. Zerr et al., 1990) and the ocelli are the photoreceptors (which robustly express elav; Robinow and White, 1991). At the majority of other locations in the brain, $\beta$-galactosidase-expressing cells were elav negative. Thus, cells located at the margins of cortex and neuropil in the optic lobes and the central brain (Fig. 2), within the lamina (Fig. $2 C, G$ ) and central brain neuropil (Fig. $2 I$ ), and in the inner chiasm (Fig. 2C,H) did not coexpress this neuronal cell marker. Prominent exceptions to this were the LCs and the dorsalmost cortical cells described previously. As shown in Figure 2, $C-E$, we found that LCs belonging to both the relatively dorsal (Fig. $2 D)$ and the more ventral of these LC clusters (see above; Fig. $2 C, E$ ) expressed both $\beta$-galactosidase and the ELAV protein. This also appeared to be the case for the smaller cells located in the dorsalmost cortex of the central brain (Fig. $2 A, B$ ), although fewer examples of these were obtained, as these cells are more difficult to find (see above).

Although the LCs and the dorsalmost cells were not the only $\beta$-galactosidase-expressing cells found within the cortex, they were the only ones to also express elav. Thus, other cortical $\beta$-galactosidase-positive cells found in the same general location as that of the LCs (Fig. $2 E$ ), or within the cortex of the lobula plate optic lobe (Fig. $2 H$ ) and the central brain (Fig. 2I), were always elav negative.

The results obtained in the current double-label experiments strongly suggest that, within the CNS, per-expressing cells belong to at least two separate classes, (putative) neuronal and (putative) glial, based on the coexpression of the elav gene product.

In the thoracic and abdominal ganglia, we were unable to find $\beta$-galactosidase-immunoreactive cells that were elav positive (Fig. $2 J$ ). This was the case for cells located within the neuropil, at the borders between cortex and neuropil, as well as for those located within the cortex. In these ganglia, in contrast to the brain, no strongly per-immunoreactive cells have been described (cf. Siwicki et al., 1988).

Anti-per/anti-elav double labeling of wild-type flies revealed results identical to those described above, although the staining of anti-per immunoreactivity was weaker and had higher background than that of anti- $\beta$-galactosidase in the transformants. Thus, as shown in Figure $2 K$, for instance, the LCs were elav positive, while the comparatively less intensely stained cell at the margin of the medulla neuropil were elav negative.

\section{Mosaic mapping of the requirement of per gene expression for the manifestation of a circadian rhythm of locomotor activity}

The mapping of the focus of per's action is based on the correlation between a mosaic animal's rhythm phenotype and its spatial pattern of per expression (visualized through the expression of per promoter-driven $\beta$-galactosidase activity).

\section{Rhythms in per $^{+}$per- $\beta$ gal $\|$ per ${ }^{01}$ (test) mosaics}

Figure 4, $A$ and $B$, shows, respectively, the distribution of power as a function of period, and width as a function of power for all the per $^{+}$per- $\beta g a l \| p e{ }^{\prime \prime}$ (test) mosaics that had a statistically significant period. This distribution has been superimposed over that obtained for all the $p_{e r}^{+}$per- $\beta g a l / p^{0}{ }^{0 I}$ flies that were tested, and all the $p^{01}{ }^{01}$ flies that had a statistically significant period.

Figure $4 \mathrm{~A}$ shows that the phenotype of $\mathrm{per}^{+} \mathrm{per}-\beta \mathrm{gal} / \mathrm{per}^{\mathrm{ol}}$ flies was characterized by period values that are tightly clustered 


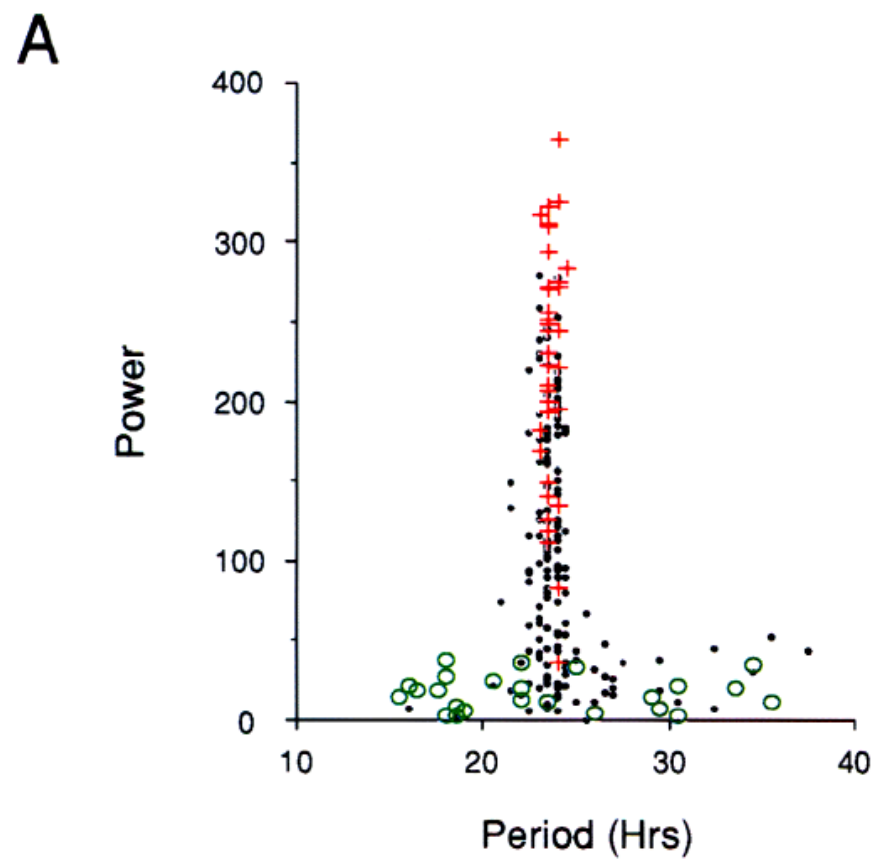

B
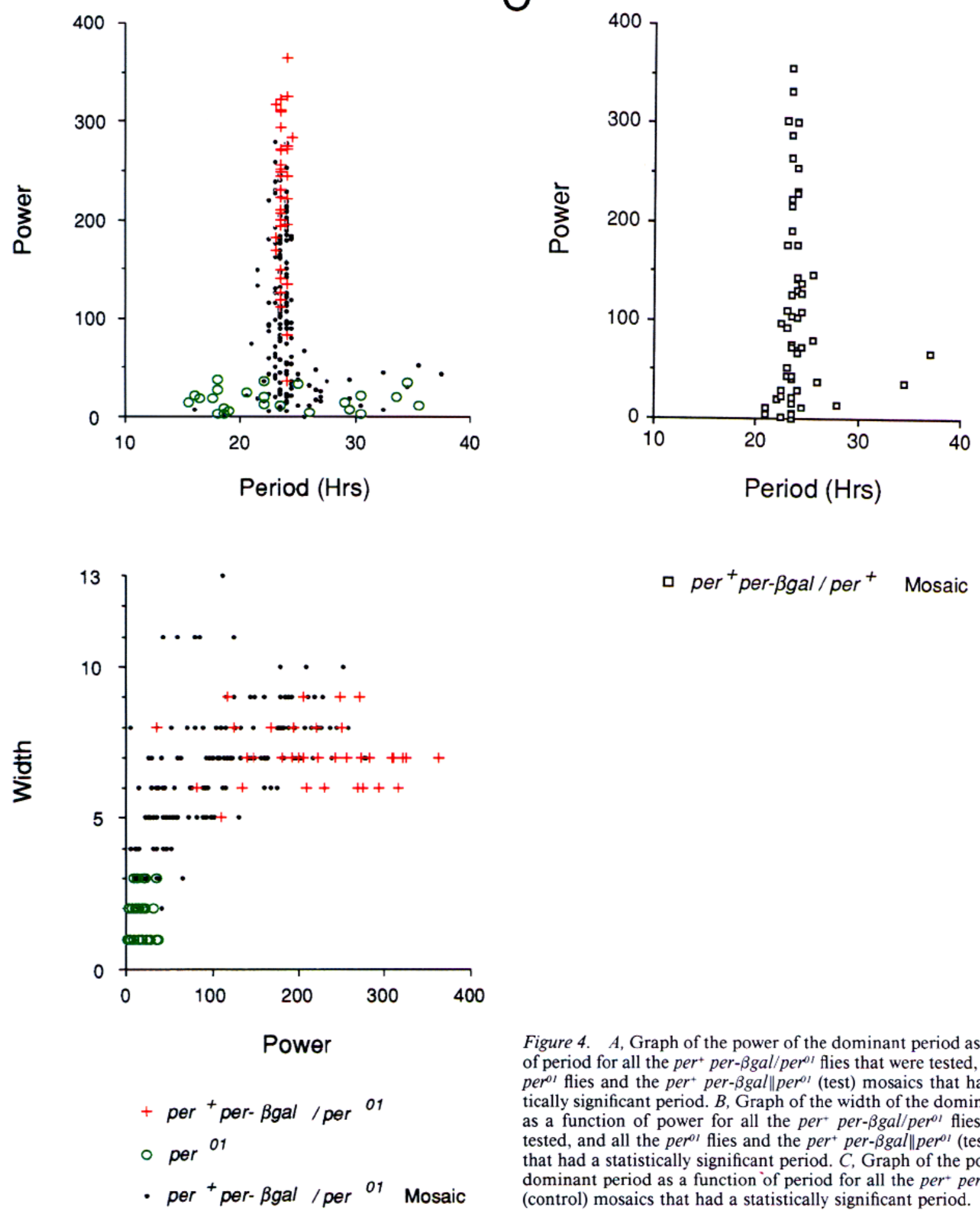

ㅁ per $^{+}$per-Bgal/per ${ }^{+}$Mosaic

around $24 \mathrm{hr}$ and by power values that are mostly greater than 100. In contrast, the periodicities of per ${ }^{\circ l}$ flies were, when present, of low power and ranged in value between 15 and $35 \mathrm{hr}$ (cf. Hamblen et al., 1986). In addition, Figure $4 B$ reveals that the phenotype expressed by these two alleles is entirely separable on the basis of the power and the width of the peak of their periodogram. Indeed, the periodicities of $\mathrm{per}^{+}$per-Bgal/per ${ }^{\circ}$ flies had amplitudes of at least 50 and/or widths greater than 5

Figure 4. A, Graph of the power of the dominant period as a function of period for all the per+ per-Bgal/per" flies that were tested, and all the

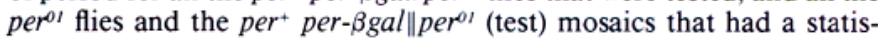
tically significant period. $B$, Graph of the width of the dominant period as a function of power for all the per per- $\beta$ gal/perol flies that were

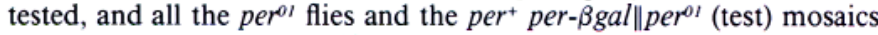
that had a statistically significant period. $C$, Graph of the power of the dominant period as a function of period for all the per ${ }^{+}$per- $\beta g a l \| p e r^{+}$ (control) mosaics that had a statistically significant period.

half-hour bins, wherease those of per ${ }^{0 \prime}$ animals had, when present, amplitudes of less than $\sim 40$ and widths that were strictly less than 4 bins. These data have been summarized in Tables 1 and 2.

In contrast to the separability of the phenotypes associated with these two alleles, Figure $4, A$ and $B$, reveals that the phenotypes of per $^{+}$per- $\beta$ gal $\|$ perol (test) mosaics spanned the range defined by per $^{+}$per-Bgal/perol-influenced and per ${ }^{\circ /}$-influenced 


\begin{tabular}{|c|c|c|c|c|c|c|c|c|}
\hline Genotype & $N$ & $N_{\mathrm{AR}}$ & $N_{\mathrm{RW}}$ & $N_{n}$ & $\% R$ & $\begin{array}{l}\text { Period } \\
(\mathrm{hr} \pm \text { SEM) }\end{array}$ & $\begin{array}{l}\text { Power } \\
( \pm \text { SEM })\end{array}$ & $\begin{array}{l}\text { Width } \\
(+ \text { SFM })\end{array}$ \\
\hline per ${ }^{+}$per-ßgaliper"t & 22 & 0 & 0 & 22 & 100 & $23.6 \pm 0.07$ & $247 \pm 14$ & $7.0 \pm 0.2$ \\
\hline per ${ }^{+}$per-Bgal/per ${ }^{\prime \prime \prime} ;$ pall + & 10 & 0 & 0 & 10 & 100 & $23.6 \pm 0.1$ & $184 \pm 21$ & $7.7 \pm 0.2$ \\
\hline 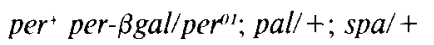 & 6 & 0 & 0 & 6 & 100 & $23.7 \pm 0.1$ & $185 \pm 37$ & $6.8 \pm 0.3$ \\
\hline 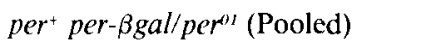 & 38 & 0 & 0 & 38 & 100 & $23.6 \pm 0.05$ & $220 \pm 12$ & $7.1 \pm 0.2$ \\
\hline
\end{tabular}

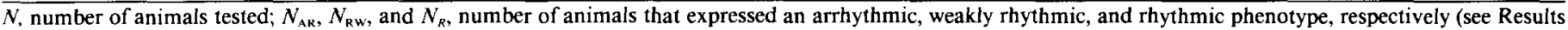

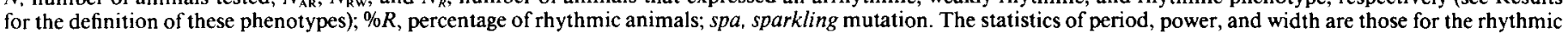
animals (see Materials and Methods).

rhythmicities, and they bridged the region within which the rhythms found in these two control genotypes do not overlap. Moreover, it shows that these animals could have combinations of period, power, and width values that were never seen in per $^{+}$per- $\beta$ gal/per ${ }^{o I}$ or per ${ }^{\circ 1}$ control flies. Thus, for instance, there are examples of animals that expressed periodicities of $\sim 22 \mathrm{hr}-$ which are well outside the normal circadian range-with powers of over 100 . Likewise, there are cases of mosaic animals that displayed a very wide peak (e.g., $>10$ ) yet have a power of less than 100 associated with it. The phenotypes expressed by these mosaics are summarized in Table 3.

\section{Rhythms in per $^{+}$per- $\beta$ gall||per ${ }^{+}$(control) mosaics}

In control mosaics, the pal-induced somatic loss of the per $^{+}$per- $\beta$ gal chromosome results in a mosaic animal that is, while part haplo-X, genotypically per in all tissues. In spite of this, the results summarized in Table 4 show that $32 \%$ (17 of 53) of these animals were arrhythmic. This frequency is much higher than the arrhythmicity that is seen in $p^{2} r^{+}$flies, which, in our stocks, is at most 5\% (Hamblen et al., 1986; Dushay et al., 1989; Hamblen-Coyle et al., 1989; Ewer et al., 1990; Liu et al., 1991; see Table 10). In addition, and as was the case for the test mosaics, the periodicities of rhythmic control mosaics were much more variable than those expressed by nonmosaic animals of the same genotype. This is illustrated in Figure $4 C$. It can also be inferred from the relatively high variance associated with the average period of rhythmic control mosaics, as shown in Table 4, compared to that for wild-type flies (Hamblen et al., 1986; Dushay et al., 1989; Hamblen-Coyle et al., 1989; Ewer et al., 1990; see Table 10).

Results of experiments designed to investigate the cause of the arrhythmicity found in $p e r^{+}$per- $\beta g a l \| p e r^{+}$mosaics will be presented in a later section of the Results. In this context, the significance of this finding is that arrhythmicity in a test mosaic is uninterpretable. Indeed, there is no way of distinguishing the cases of arrhythmicity that are due to the absence of per expression at an essential site from those that result from mosaicism per se. This is especially true in this study, as the frequency of arrhythmicity in test mosaics (Table 3 ) was similar to that obtained in control mosaics (Table 4; see also below).

The occurrence of arrhythmicity due to mosaicism can be revealed in test mosaics by finding arrhythmic animals bearing a patch of mutant tissue that could be included within that found in rhythmic mosaics. An example of one such case is shown in Figure 5. For this animal, the mutant patch was restricted to one side of the head. However, this pattern of expression would not be expected to result in arrhythmicity. Indeed, an animal could be entirely mutant on one side and yet be rhythmic (Fig. 6; see also Table 5).
In addition to arrhythmicity, mosaicism per se could also affect the strength of the rhythmicity expressed by mosaics. In control mosaics, this is illustrated by the large scatter in the distribution of period versus power (Fig. 4C). In test mosaics, it is revealed by finding that there was, by and large, no correlation between the size and location of a mutant patch and the animal's rhythm phenotype. Thus, for example, in the mosaic shown in Figure 7 , mutant tissue occurred in the thorax and the abdomen; none could be detected in the head (which includes the focus for this behavior; Konopka et al., 1983; see also below). However, this fly expressed a rhythm that was weaker (and of shorter period) than that expressed by the fly shown in Figure 6 , in which staining was restricted to one side of the head.

\section{Criteria for classifying the rhythm phenotype of per $^{+}$per- $\beta$ gal $\|$ per ${ }^{01}$ mosaics}

Given the characteristics of the locomotor activity rhythms expressed by per ${ }^{+}$per- $\beta$ gal $\| p e r^{\prime \prime}$ mosaics (compare Fig. $4 A, B$ ), it was necessary to establish quantitative criteria by which to classify the phenotypes obtained in these animals. This classification was based on the value of the power and the width associated with the periodicity of the record (when present). Thus, animals for which the power was less than 40 and the width was strictly less than 4 half-hour bins were classified as arrhythmic (strictly speaking, per'l-like), whereas those for which these values were greater than 40 and 4 , respectively, were called rhythmic

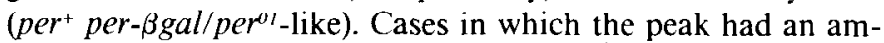
plitude that hovered slightly below 40 were classified as rhythmic if their width was greater than 5 . These criteria separate

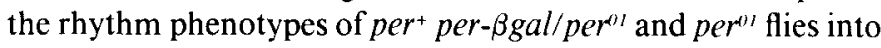
two nonoverlapping domains (compare Fig. 4A, $B$, Table 3 ). Mosaic animals that displayed intermediate phenotypes, for instance animals with peaks whose width was less than 3 yet had an amplitude of over 40 , were found in $\sim 6 \%$ of the cases (compare Fig. 4). These cases were classified as weakly rhythmic.

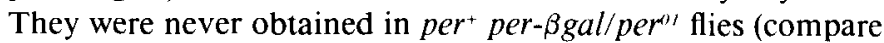
Fig. $4 B$, Table 1).

Table 2. Period, power, and width in perot cho $s n$ flies

\begin{tabular}{lcccc} 
Parameter & Minimum & Maximum & Median & $\begin{array}{l}\text { Average } \\
\pm \text { SEM }\end{array}$ \\
\hline Period (hr) & 15.5 & 35.5 & 22.0 & $23.1 \pm 1.2$ \\
Power & 2.7 & 37.0 & 14.6 & $16.8 \pm 2.1$ \\
Width & 1 & 3 & 2.0 & $1.8 \pm 0.15$
\end{tabular}

Total number of flies tested, 29; number of arrhythmic (power $<0$ ) flies, 3 . This table shows the distribution of period, power, and width values in remaining flies. 


\begin{tabular}{|c|c|c|c|c|c|c|}
\hline $\begin{array}{l}\text { Proportion } \\
\text { of per } \\
\text { tissue }\end{array}$ & Phenotype $^{a}$ & $N$ & $\%$ & $\begin{array}{l}\text { Period } \\
(\mathrm{hr} \pm \mathrm{SEM})\end{array}$ & $\begin{array}{l}\text { Power } \\
( \pm \text { SEM })\end{array}$ & $\begin{array}{l}\text { Width } \\
( \pm \text { SEM })\end{array}$ \\
\hline \multirow[t]{3}{*}{0.0} & AR & 4 & 100 & & & \\
\hline & RW & 0 & 0 & - & - & - \\
\hline & $\mathrm{R}$ & 0 & 0 & - & - & - \\
\hline \multirow[t]{3}{*}{0.1} & AR & 14 & 78 & & & \\
\hline & RW & 0 & 0 & - & - & - \\
\hline & $\mathrm{R}$ & 4 & 22 & $32.7 \pm 2.3$ & $41 \pm 4$ & $7.0 \pm 1.5$ \\
\hline \multirow[t]{3}{*}{0.5} & AR & 51 & 35 & & & \\
\hline & RW & 9 & 6 & $24.6 \pm 0.8$ & $21 \pm 4$ & $4.9 \pm 0.4$ \\
\hline & $\mathbf{R}$ & 84 & 58 & $23.7 \pm 0.2$ & $132 \pm 7$ & $7.0 \pm 0.2$ \\
\hline \multirow[t]{3}{*}{0.9} & AR & 0 & 0 & & & \\
\hline & RW & 1 & 25 & 24.5 & 33 & 4 \\
\hline & $\mathbf{R}$ & 3 & 75 & $23.7 \pm 0.6$ & $172 \pm 30$ & $8.3 \pm 0.3$ \\
\hline \multirow[t]{3}{*}{1.0} & $\mathrm{AR}$ & 0 & 0 & & & \\
\hline & RW & 1 & 4 & 25.5 & 66 & 3 \\
\hline & $\mathbf{R}$ & 22 & 96 & $23.9 \pm 0.1$ & $136 \pm 14$ & $7.9 \pm 0.3$ \\
\hline \multirow[t]{3}{*}{ Total } & AR & 69 & 36 & - & - & - \\
\hline & RW & 11 & 6 & $24.6 \pm 0.7$ & $26 \pm 5$ & $4.6 \pm 0.4$ \\
\hline & $\mathbf{R}$ & 113 & 59 & $24.1 \pm 0.2$ & $130 \pm 6$ & $7.2 \pm 0.2$ \\
\hline
\end{tabular}

${ }^{a}$ For abbreviations, see Table 1 notes.

$\beta$-Galactosidase staining in $\operatorname{per}^{+}$per- $\beta$ gal $\|$ per ${ }^{01}$ (test) and per $^{+}$ per- $\beta$ gal $\|$ per $^{+}$(control) mosaic flies

Except at the border between diplo- and haplo- $X$ tissue, staining in mosaic flies was qualitatively identical to that seen in nonmosaic flies of the same genotype. In the gynandromorphs, the borders of a patch of null tissue were always clearly discernible. In addition, the staining phenotype of structures that were mutant for the cuticular markers was consistent with their external phenotype (e.g., a cho patch seen at the surface of the eye resulted in a null patch in the corresponding photoreceptors).

However, the extent of internally mutant tissue in mosaics could not be accurately predicted from the animal's external phenotype (cf. Hall et al., 1976; Kankel and Hall, 1976). For instance, out of 88 mosaics that had mutant tissue restricted to one side of the head, 35 had, internally, mutant tissue on the contralateral side. Likewise, out of 29 animals that were almost entirely mutant except for a small crescent of $c h o^{+}$in one eye, 11 were not entirely mutant internally on the contralateral side.

\section{$\beta$-Galactosidase staining in nonmosaic animals}

per $^{+}$per- $\beta$ gal $/$ per $^{01}$ and per $^{01}$ flies. $\beta$-Galactosidase expression in the nervous system of the head of per- $\beta$ gal-bearing transformants has been described previously (Liu et al., 1988, 1991; see above). In the head of pero' flies, X-gal staining occurred only as a reticulate-like staining at the border between the lamina and the photoreceptors (not shown; compare Fig. 6). This staining did not occur in all the flies of this genotype and did not appear to be associated with cell bodies; its origin is unknown. It was not obtained using an anti- $\beta$-galactosidase antibody (not shown) and thus probably does not result from the activity of $\beta$-galactosidase.

\section{The mapping}

Two hundred and thirty test mosaics were generated for this study. Of these, 193 survived locomotor activity testing and reentrainment (see Materials and Methods) and were successfully sectioned and stained. The large majority of these were

\begin{tabular}{|c|c|c|c|c|c|c|c|c|}
\hline $\begin{array}{l}\text { Pro- } \\
\text { portion } \\
\text { of } \\
\text { diplo-X } \\
\text { tissue }\end{array}$ & $N$ & $N_{\text {AR }}$ & $N_{\mathrm{RW}}$ & $N_{\mathrm{R}}$ & $\% R$ & $\begin{array}{l}\text { Period } \\
(\mathrm{hr} \pm \mathrm{SEM})\end{array}$ & $\begin{array}{l}\text { Power } \\
( \pm \text { SEM })\end{array}$ & $\begin{array}{l}\text { Width } \\
( \pm \text { SEM) }\end{array}$ \\
\hline 0.0 & 2 & 1 & 0 & 1 & 50 & 37.0 & 67 & 9 \\
\hline 0.5 & 48 & 16 & 1 & 31 & 64 & $24.2 \pm 0.4$ & $153 \pm 16$ & $7.3 \pm 0.3$ \\
\hline 1.0 & 3 & 0 & 0 & 3 & 100 & $23.7 \pm 0.4$ & $149 \pm 92$ & $7.7 \pm 0.3$ \\
\hline Total & 53 & 17 & 1 & 35 & 66 & $24.5 \pm 0.5$ & $151 \pm 16$ & $7.4 \pm 0.3$ \\
\hline
\end{tabular}




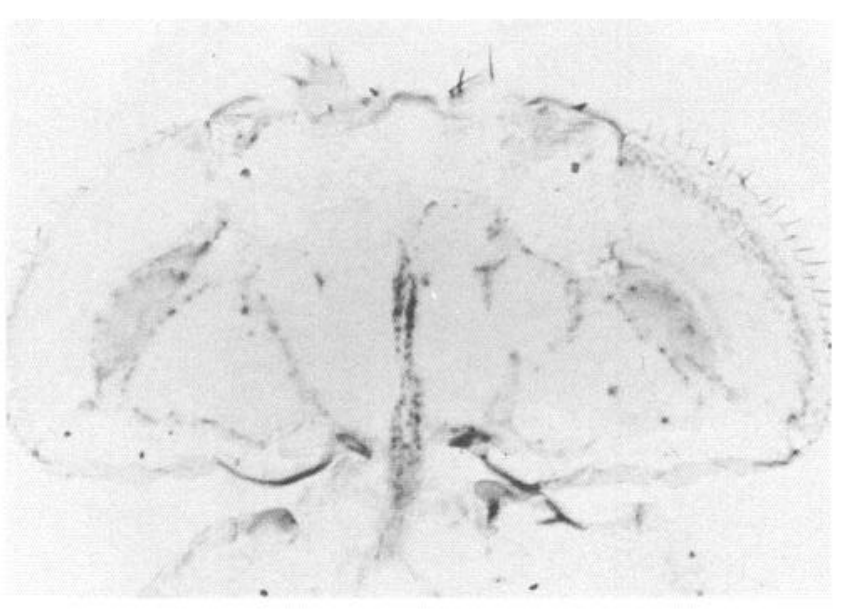

\section{Time of Day (Hrs)}
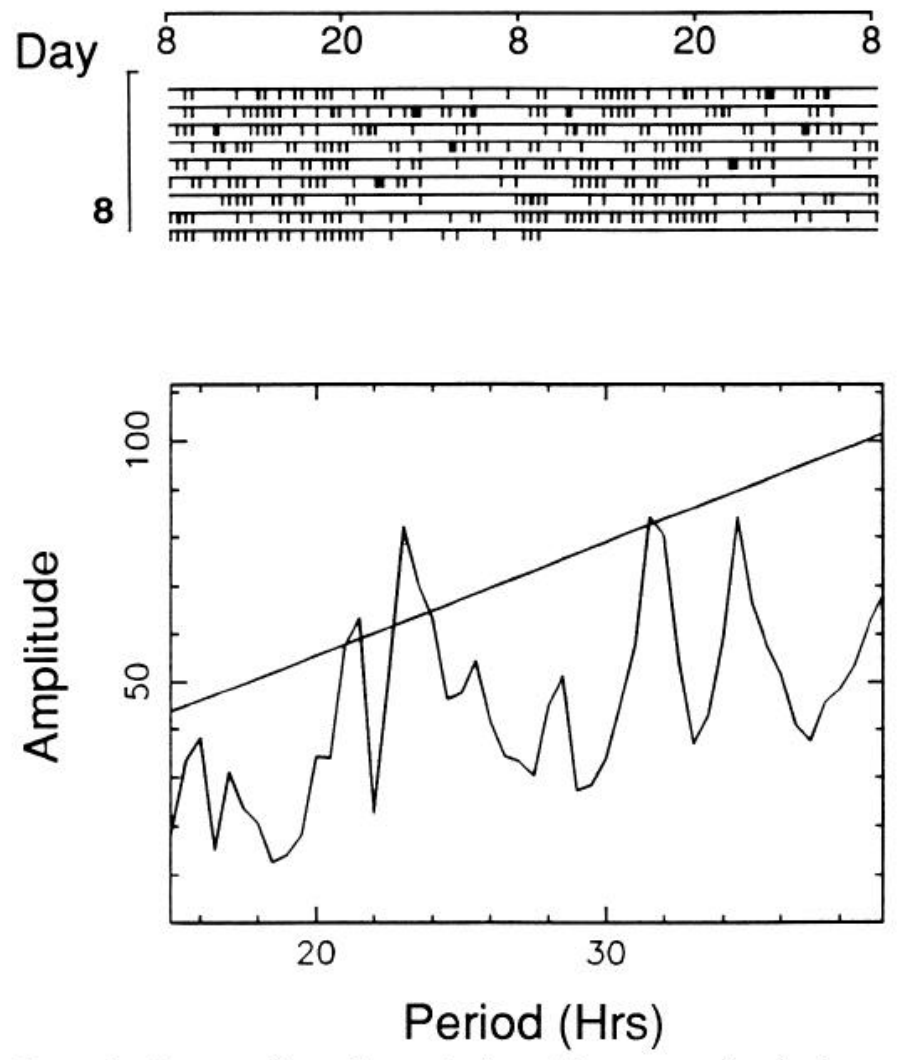

Figure 5. Pattern of per-driven $\beta$-galactosidase expression (top), actogram (middle), and periodogram (bottom) of per ${ }^{+}$per- $\beta$ gal $\|$ per ${ }^{o t}$ mosaic MJE102. In this and all figures of this type, the pattern of staining that is seen on the particular section that is shown is representative of the distribution of per ${ }^{+}$and perol tissue that was observed throughout the whole head of the animal.

complete; that is, they included all the sections of the fly's head. The remaining ones were complete enough to allow for an accurate reconstruction of the pattern of staining; there were usually never more than two consecutive sections missing. Strong statements (below) are never based exclusively on animals for which critical sections were missing.

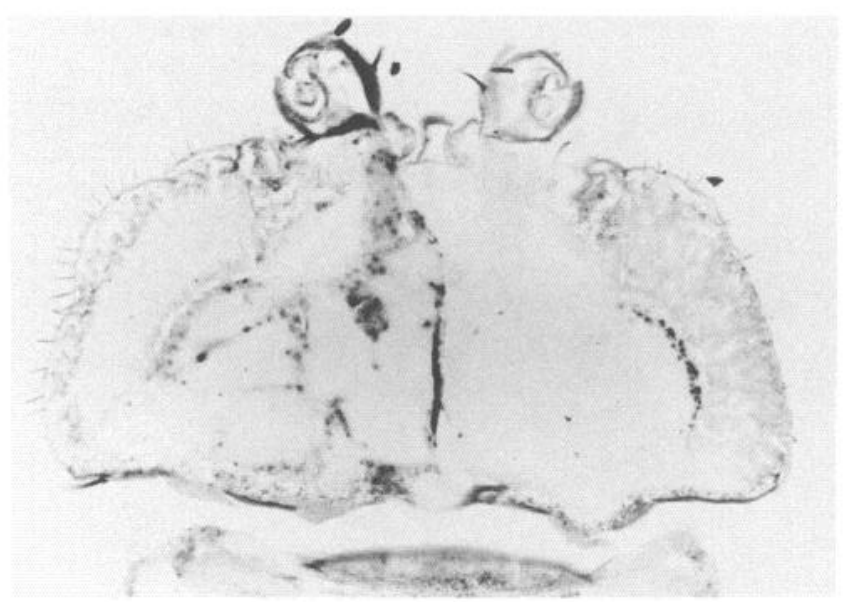

Time of Day (Hrs)
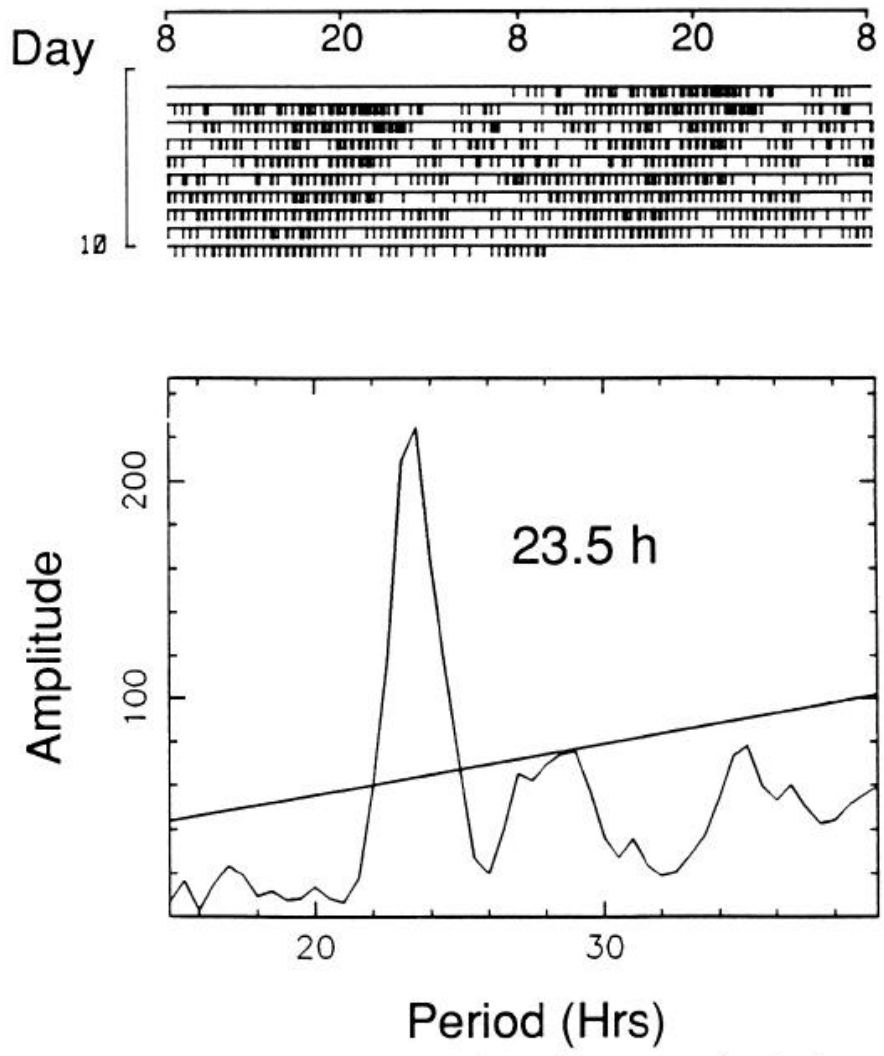

Figure 6. Pattern of per-driven $\beta$-galactosidase expression (top), actogram (middle), and periodogram (bottom) of per ${ }^{+}$per- $\beta$ gal $\|$ per" mosaic MJE188.

Given that mosaicism could, in itself, result in the expression of an arrhythmic phenotype, arrhythmicity in a test mosaic is uninterpretable. Thus, the mapping carried out here can only reveal in which region(s) of the fly per expression is sufficient for rhythmicity. Indeed, it must be based only on the analysis of the pattern of expression found in rhythmic animals.

The focus for rhythmicity (probably) lies in the head. Figure 8 shows the distribution of rhythm phenotypes as a function of 


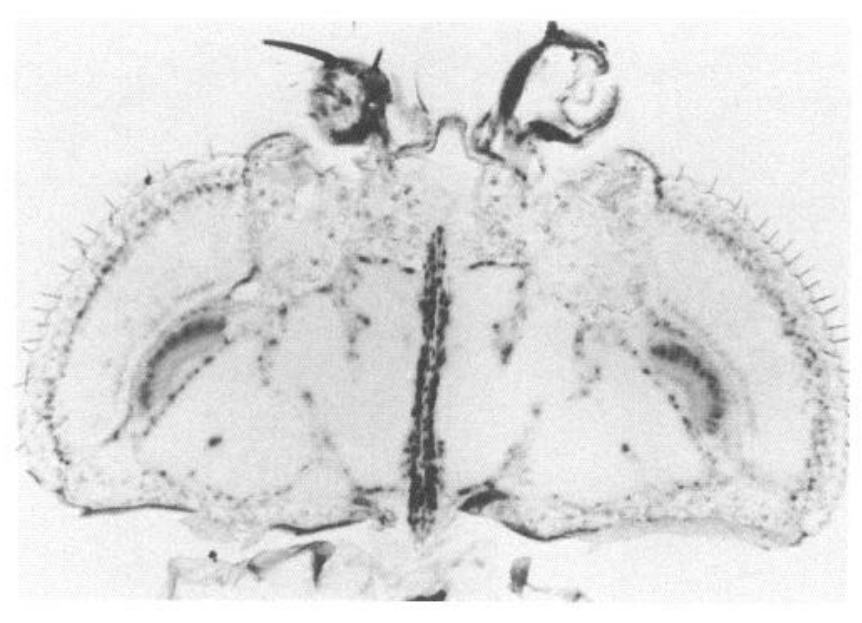

Time of Day (Hrs)
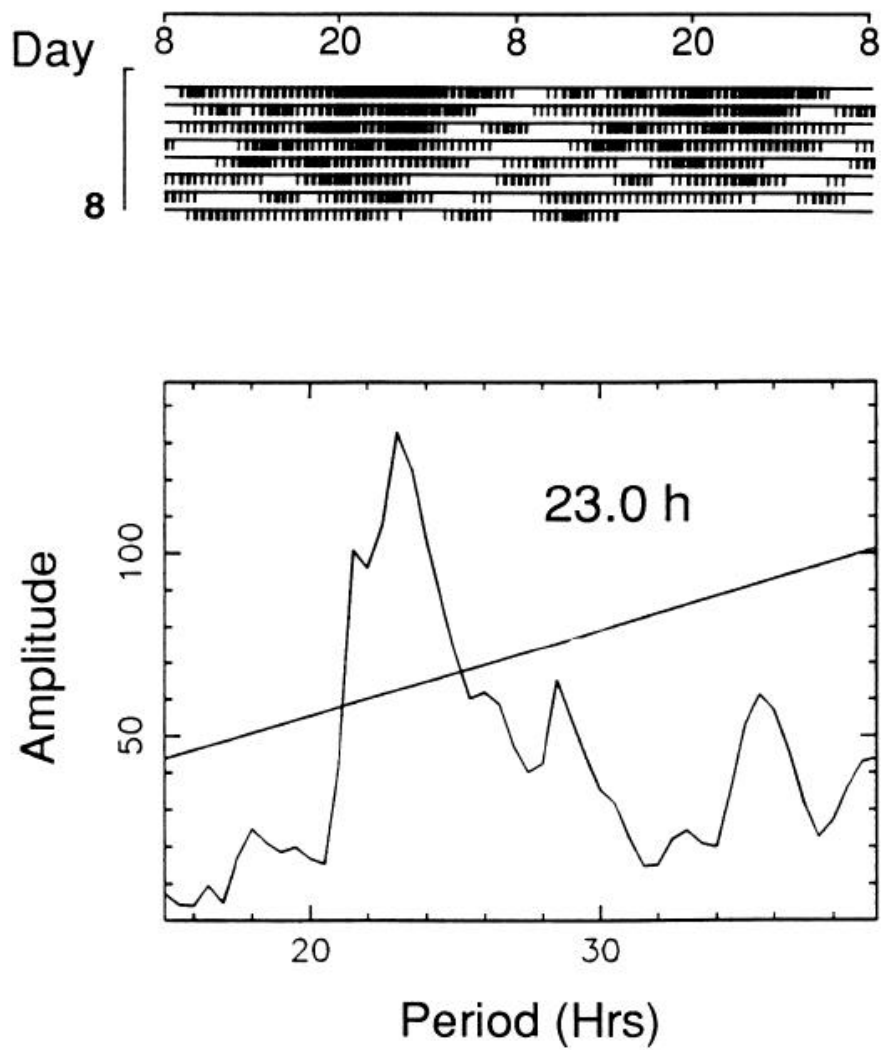

Figure 7. Pattern of per-driven $\beta$-galactosidase expression (top), actogram (middle), and periodogram (bottom) of per $^{+}$per- $\beta g a l \| p e r^{\circ 1}$ mosaic MJE85.

the extent of per expression in the head (assessed grossly and qualitatively; see Materials and Methods); these data are summarized in Tables 3 and 4 . They show that all ( 23 of 23$)$ of the animals that had no mutant tissue in the head (and were thus mosaic in the thorax and/or the abdomen) were rhythmic (one of them was weakly rhythmic). Figure 8 also shows that the frequency of arrhythmicity among mosaics increases with the size of the mutant patch. In particular, all (4 of 4; compare Tables 3,4 ) animals that were entirely mutant in the head were

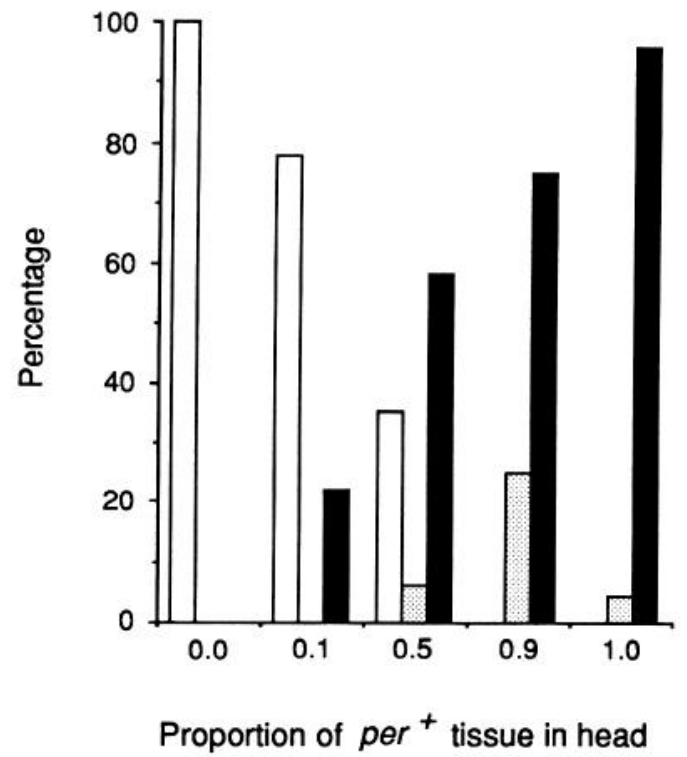

\section{Arrhythmic \\ Weakly rhythmic \\ Rhythmic}

Figure 8. Percentage of per $^{+}$per- $\beta g a l \| p e{ }^{0 \prime}$ mosaic animals that expressed an arrhythmic, weakly rhythmic, or rhythmic phenotype as a function of the proportion of per tissue in the head. These data, including the number of animals tested and the average period, power, and width for the animals that expressed a weakly rhythmic or a rhythmic phenotype, are summarized in Table 3.

arrhythmic. Such correlations were not seen when the data were organized as a function of the size of mutant patch in the thorax or the abdomen (not shown).

These results indicate that the requirement for per expression and the arrhythmicity induced by mosaicism per se both map to the head. Indeed, all the animals that were genetically normal on the external surface of the head were rhythmic, and all the animals that had a completely mutant head were arrhythmic. These results are consistent with those obtained by Konopka et al. (1983). They are also in agreement with those obtained by one of us, in a study involving $193 \mathrm{per}^{+} \| \mathrm{per}^{\circ l}$ mosaics that were marked only on the external cuticle (Hamblen-Coyle, unpublished observations).

Regarding the effects that mosaicism had on an animal's rhythm phenotype, the data shown in Figure 8 are also consistent with those obtained in control mosaics (compare Table 4). Thus, in the latter, all those for which the head was genetically normal externally were rhythmic (although only three of such animals were tested).

A comparison of Tables 3 and 4 also reveals that the frequency of arrhythmicity was similar in control (17 of 53, or $35 \%)$ and test (69 of 193 , or $36 \%$ ) mosaics. Thus, it is possible that most, if not all, of the cases of arrhythmicity in test mosaics were due to mosaicism per se. This would imply that it is very difficult to make a fly arrhythmic from lack of per expression. Indeed, as shown below, we have found that a small patch of per+expressing tissue can be sufficient for rhythmicity to be manifest.

Structures in which per expression is dispensable for rhythmicity. In order to map the focus for the action of the per gene 


\begin{tabular}{|c|c|c|c|c|c|}
\hline $\begin{array}{l}\text { Structures expressing per on one side } \\
\text { (or less) }\end{array}$ & $\begin{array}{l}\text { Mosaic's } \\
\text { name }\end{array}$ & $\begin{array}{l}\text { Period } \\
\text { (hr) }\end{array}$ & Power & Width & Comments $^{a}$ \\
\hline \multirow[t]{12}{*}{ 1. Ocelli, eyes, and optic lobes } & mje200 & 24.0 & 22.4 & 5 & $+\mathrm{C}, \mathrm{Cb}(\mathrm{I})$ \\
\hline & MJE226 & 34.5 & 29.8 & 7 & $\mathrm{Cb}(\mathrm{I}),+\mathrm{C}_{\mathrm{L}}$ \\
\hline & MJE21 & 24.0 & 43.9 & 4 & $+\mathrm{C}, \mathrm{Cb}(\mathrm{I})$ \\
\hline & MJE6 & 32.5 & 44.2 & 6 & $\mathrm{C}_{\mathrm{L}}, \mathrm{Cb}(1)$ \\
\hline & MJE162 & 35.5 & 51.7 & 4 & $+\mathrm{C}_{\mathrm{L}}$ \\
\hline & M.IE124 & 24.0 & 107 & 7 & $+\mathrm{C}_{\mathrm{L}}, \mathrm{M}(2)$ \\
\hline & MJE166 & 24.0 & 124 & 7 & $\mathrm{Cb}(\mathrm{I}),+\mathrm{C}_{\mathrm{L}}$ \\
\hline & MJE94 & 23.0 & 126 & 11 & $\mathrm{M}(1)$ \\
\hline & MJE198 & 23.5 & 161 & 7 & $+\mathrm{C}, \mathrm{Cb}(3)$ \\
\hline & MJEI 84 & 23.0 & 130 & 5 & $\mathrm{M}(2)$ \\
\hline & MJE132 & 23.5 & 168 & 6 & $+\mathrm{C}, \mathrm{Cb}(6)$ \\
\hline & MJE230 & 24.0 & 217 & 7 & $+\mathrm{C}, \mathrm{Cb}(\mathrm{I}), \mathrm{M}(\mathrm{l})$ \\
\hline \multirow[t]{10}{*}{ 2. Ocelli, eyes, optic lobes, and brain } & mje53 & 22.5 & 5.5 & 4 & $+\mathrm{C}_{\mathrm{L}}$ \\
\hline & mje 149 & 30.5 & 11.2 & 4 & $+\mathrm{C}_{\mathrm{L}}$ \\
\hline & mje 142 & 24.5 & 36.4 & 4 & $+\mathrm{C}_{\mathrm{L}}$ \\
\hline & MJE229 & 37.5 & 43.9 & 11 & $+\mathrm{C}_{\mathrm{L}}$ \\
\hline & MJEI85 & 26.5 & 47.6 & 4 & $+\mathrm{C}_{\mathrm{L}}$ \\
\hline & MJE101 & 22.5 & 92.2 & 6 & $+\mathrm{C}$ \\
\hline & MJE143 & 22.5 & 93.5 & 5 & $+\mathrm{C}_{\mathrm{L}}$ \\
\hline & MJE214 & 21.5 & 132 & 7 & $+\mathrm{C}$ \\
\hline & MJE82 & 21.5 & 149 & 7 & $+\mathrm{C}$ \\
\hline & MJE188 & 23.5 & 161 & 6 & $+\mathrm{C}$ \\
\hline
\end{tabular}

Within each group, animals are listed by increasing power values. The names of animals expressing weak rhythmicities (see Results) are in lower case.

${ }^{a} \mathrm{I}$, Patch of mutant tissue on ipsilateral side; $\mathrm{C}$, patch $\left(\mathrm{C}_{1}\right.$, large patch) of mutant tissue on contralateral side; $\mathrm{B}$, patch of mutant tissue on both sides $\left(B_{L}\right.$, large patch); $C b$, central brain; $M$, medulla. Numbers in parentheses indicate the number of cells that were stained within an otherwise entirely mutant structure.

within the head, we determined whether particular patterns of expression were compatible with rhythmicity.

The following two general questions were asked. (1) Is expression in only one side of the head compatible with rhythmicity? If this were so, and assuming that the focus for this behavior is a paired one, this result would indicate that per expression in only one of these brain structures is sufficient for rhythmicity. (2) Which structures of the brain can be bilaterally null in a rhythmic animal? Finding such an animal would demonstrate that per expression in these structures is not essential for rhythmicity. If this behavior had a discrete focus (or foci), this result would indicate that this focus (or foci) lies elsewhere. The structures considered were the eyes, ocelli, and the optic lobes. In addition, we examined the requirement for per expression in the neurons located in the dorsalmost cortex of the central brain. The relevance of per expression in the LCs will be discussed in a later section of the Results.

Operationally, this mapping was done by searching the database for Hies that showed the desired pattern of expression and had a rhythmic phenotype.

The results of this analysis are presented in Tables 5 and 6 . For each distribution examined, a list is given of all the animals that showed the desired spatial pattern of expression and expressed a rhythmic phenotype. The animals listed include only those for which a given structure was entirely null (slight exceptions are indicated under Comments). For many of the animals listed, the mutant patch included more than the structure that was considered (e.g., among the animals that are listed as being bilaterally null for the lamina optic lobe, some may also have, e.g., a mutant patch in the adjacent medulla, etc.; compare Table 7). Mosaics are designated by "MJE" followed by an arbitrary number.

The results summarized in Tables 5 and 6 show that per expression in one side of the brain is sufficient for thythmicity (Table 5). In addition, they reveal that expression in the eyes, the ocelli, and the optic ganglia is not essential for a rhythmic phenotype to be manifest (Table 6).

In some cases (e.g., for the medulla), the only rhythmic animals found for which a given structure was bilaterally null did not express a strong rhythm. These results are difficult to interpret. (1) These animals (e.g., MJE226 and MJE229, which were bilaterally null in the medulla) were also null or almost null in most of the rest of brain (Tables 5, 6; see also Table 7), and thus the weak rhythmicity of these animals could be due to the lack of per expression in more than one structure; and (2) the power of the rhythms obtained in mosaics did not seem to bear any relationship to the distribution of per expression (see above). Moreover, for cases such as these in which the animal had a very large mutant patch, weak rhythms might be expected based on the results obtained in control mosaics. Indeed, as shown in Table 4, out of the two flies that were completely haplo- $X$ in the head (yet were per in all tissues), one of them was arrhythmic and the other one had a weak (power, 67) and long $(37.0 \mathrm{hr}$ ) period rhythm. Thus, it is not possible to tell whether the test mosaic animals that showed no staining in the medulla expressed weak rhythms because of the lack of per expression in this structure, or because they were also null in many other regions of the brain, or whether this was simply a 
Table 6. List of animals with structures showing no per expression on either side

Structure bilaterally null

4. Cells in inner optic chiasm
2. Eyes

3. Lamina

1. Ocelli

5. Lobula

6. Lobula plate

\begin{tabular}{|c|c|c|c|c|}
\hline $\begin{array}{l}\text { Mosaic's } \\
\text { name }\end{array}$ & $\begin{array}{l}\text { Period } \\
\text { (hr) }\end{array}$ & Power & Width & Comments $^{a}$ \\
\hline MJE226 & 34.5 & 29.8 & 7 & \\
\hline mje235 & 26.0 & 31.9 & 5 & \\
\hline mjel42 & 24.5 & 36.4 & 4 & \\
\hline MJE229 & 37.5 & 43.9 & 11 & \\
\hline MJE6 & 32.5 & 44.2 & 6 & \\
\hline MJE185 & 26.5 & 47.6 & 4 & \\
\hline MJE97 & 24.0 & 74.3 & 6 & \\
\hline MJE101 & 22.5 & 92.2 & 6 & \\
\hline MJE 174 & 23.5 & 109 & 7 & \\
\hline M.JE1 84 & 23.0 & 130 & 5 & \\
\hline MJE214 & 21.5 & 132 & 7 & \\
\hline MJE150 & 23.5 & 147 & 8 & \\
\hline MJE159 & 23.5 & 203 & 7 & \\
\hline MJE230 & 24.0 & 217 & 7 & \\
\hline MJE1 56 & 23.0 & 259 & 8 & \\
\hline MJE226 & 34.5 & 29.8 & 7 & \\
\hline mje235 & 26.0 & 31.9 & 5 & \\
\hline MJE229 & 37.5 & 43.9 & 11 & \\
\hline MJE6 & 32.5 & 44.2 & 6 & \\
\hline MJE185 & 26.5 & 47.6 & 4 & \\
\hline MJE162 & 35.5 & 51.7 & 4 & \\
\hline MJE230 & 24.0 & 217 & 7 & \\
\hline MJE226 & 34.5 & 29.8 & 7 & \\
\hline mje235 & 26.0 & 31.9 & 5 & \\
\hline MJE133 & 27.5 & 36.2 & 8 & \\
\hline MJE229 & 37.5 & 43.9 & 11 & \\
\hline MJE6 & 32.5 & 44.2 & 6 & \\
\hline MJE1 85 & 26.5 & 47.6 & 4 & \\
\hline MJE162 & 35.5 & 51.7 & 4 & \\
\hline MJE171 & 23.5 & 57.1 & 5 & \\
\hline MJE157 & 23.0 & 60.1 & 5 & \\
\hline MJE124 & 24.0 & 107 & 7 & \\
\hline MJE94 & 23.0 & 126 & 11 & \\
\hline MJE226 & 34.5 & 29.8 & 7 & \\
\hline mje235 & 26.0 & 31.9 & 5 & \\
\hline mje 142 & 24.5 & 36.4 & 4 & \\
\hline MJE229 & 37.5 & 43.9 & 11 & \\
\hline MJE6 & 32.5 & 44.2 & 6 & \\
\hline MJE185 & 26.5 & 47.6 & 4 & \\
\hline MJE162 & 35.5 & 51.7 & 4 & \\
\hline MJE124 & 24.0 & 107 & 7 & \\
\hline MJE 166 & 24.0 & 124 & 7 & \\
\hline MJE94 & 23.0 & 126 & 11 & $\operatorname{Ic}(1)$ \\
\hline MJE226 & 34.5 & 29.8 & 7 & \\
\hline mje l42 & 24.5 & 36.4 & 4 & \\
\hline MJE229 & 37.5 & 43.9 & 11 & $\operatorname{Lo}(1)$ \\
\hline MJE6 & 32.5 & 44.2 & 6 & \\
\hline MJE185 & 26.5 & 47.6 & 4 & $\operatorname{Lo}(1)$ \\
\hline MJE162 & 35.5 & 51.7 & 4 & $\operatorname{Lo}(1)$ \\
\hline MJE143 & 22.5 & 93.5 & 5 & \\
\hline MJE226 & 34.5 & 29.8 & 7 & $\operatorname{Lp}(1)$ \\
\hline mje235 & 26.0 & 31.9 & 5 & \\
\hline mjel42 & 24.5 & 36.4 & 4 & \\
\hline MJE229 & 37.5 & 43.9 & 11 & \\
\hline MJE6 & 32.5 & 44.2 & 6 & \\
\hline MJE185 & 26.5 & 47.6 & 4 & $\operatorname{Lp}(1)$ \\
\hline MJE 162 & 35.5 & 51.7 & 4 & $\operatorname{Lp}(1)$ \\
\hline MJE124 & 24.0 & 107 & 7 & \\
\hline
\end{tabular}


Table 6. Continued

\begin{tabular}{lllrrrr} 
Structure bilaterally null & $\begin{array}{l}\text { Mosaic's } \\
\text { name }\end{array}$ & $\begin{array}{l}\text { Period } \\
\text { (hr) }\end{array}$ & Power & & Width & Comments $^{a}$ \\
\cline { 1 - 4 } & MJE226 & 34.5 & 29.8 & 7 & \\
& MJE229 & 37.5 & 43.9 & 11 & \\
& MJE6 & 32.5 & 44.2 & 6 & M(1) \\
8. Dorsalmost region of the central brain & mje235 & 26.0 & 31.9 & 5 & \\
& mje142 & 24.5 & 36.4 & 4 & \\
& MJE229 & 37.5 & 43.9 & 11 & \\
& MJE6 & 32.5 & 44.2 & 6 & \\
& MJE185 & 26.5 & 47.6 & 4 & \\
& MJE162 & 35.5 & 51.7 & 4 & \\
& MJE150 & 23.5 & 147 & 8 & Cb(2) \\
\hline
\end{tabular}

For explanation of format, see Table 5 notes.

a $\mathrm{Cb}$, central brain; M, medulla; Lo, lobula; Lp, lobula plate; Ic, inner chiasm. Numbers in parentheses indicate the number of cells that were stained within an otherwise entirely mutant structure.

consequence of their having a large patch of hemizygous tissue. Nevertheless, the rhythmicity of these animals indicates that, at the very least, per expression in this structure is not necessary for rhythmicity. In reality it may not even be necessary for normal rhythms to be expressed.

No animals were found that were rhythmic yet showed no per $^{+}$expression in the central brain. However, this result does not allow one to conclude that expression in this structure is essential for rhythmicity. Indeed, no animals were recovered (irrespective of their rhythm phenotype) that were (completely) null in the central brain yet had per-expressing tissue in other regions of the anterior CNS (c.g., the optic lobes). As discussed previously, all the animals whose heads were completely mutant internally were arrhythmic (compare Table 3).

Rhythmicity in test mosaics lacking per expression in multiple structures. The data presented in Tables 5 and 6 have been rearranged in Table 7 to show that rhythmic animals could be found that lacked per expression (bilaterally) in more than one structure. For instance, MJE124 showed no expression (i.e., was bilaterally null) in both the lamina, the lobula plate, and the inner optic chiasm (in addition to being null or almost null in all the other optic lobes on one side), yet expressed a strong rhythm. A perusal of this table reveals that rhythmic animals could be found that showed no expression in any of the optic ganglia (e.g., MJE6, MJE226, and MJE229; as indicated in the Comments, these animals also had large mutant patches in the brain). These results allow one to conclude that per expression in the optic lobes is not esscntial for rhythmicity, and thus that per expression in the central brain is sufficient for rhythmicity.

The question of whether per expression in the central brain is necessary could not be addressed. Indeed, this would require having found an animal that was completely null in the central brain and had pert-expressing tissue in other regions of the brain. As noted above, no such animal was ever found, irrespective of its rhythm phenotype.

We found that a very small patch of per-expressing tissue in the head, which was mostly restricted to the subesophageal ganglion, appears to be sufficient for rhythmicity to be manifested. One example of three of such animals that were recovered is shown, together with its rhythm phenotype, in Figure 9. Other than a few solitary cells in particular optic lobes, no expression is seen other than in a small patch in the ventralmost sections of the central brain.
Detailed scoring of exceptional mosaics. We have attempted to quantify the size and specify the location of the minimal patches that were compatible with rhythmicity. To do so, we have taken a few exceptional mosaics that showed very large patches of mutant tissue yet were rhythmic (e.g., the animal shown in Fig. 9) and counted the number of stained cells present in each structure (or region; see below) in every section. These values were then quantified relative to the number of cells present in the same structure and at the same level in a nonmosaic (control) animal. The structures (and regions) that were scored are shown in Figure 10. In this more detailed description, the brain and medulla were divided into subregions that were counted separately. Thus, the anterior and posterior central brain areas were divided into two quadrants (front and lateral, and lateral and rear, for the anterior and posterior central brain, respectively). Likewise, the three borders of the medulla that exhibit stain were also scored separately (inner, outer, and the lamina/medulla border).

An attempt was also made to quantify the number of putative neurons ("lateral neurons," or LNs; Siwicki et al., 1988) that were stained in the mosaics that were scored in detail. These neurons are of interest because they are among the most conspicuous per-expressing cells within the fly's central brain and optic lobes (see above). They have been suggested to be the most likely candidates for the pacemaker cells of the fly's circadian rhythm (Siwicki et al., 1988; Zerr et al., 1990). Since the expression of the fusion gene in these LNs results in a stain that is not as discrete as that of the many per-positive cell bodies in the lateral brain region, scoring the number of these cells was difficult, and hence impractical. Instead, we scored the region within which these cells are found. The rationale for this was that if this area were entirely null (which is the case of interest), presumably the LNs within it would also be null. This region is bounded laterally by the inner margin of the medulla and the outer margin of the anterior lateral brain that is located opposite to the medulla (cf. Siwicki et al., 1988; see above). Anteriorly and posteriorly this region is bounded by the anterior region of the brain and the posterior margin of the inner medulla, respectively. This area is indicated as "Brain/medulla" in Figure 10. This region was scored as follows. For a given section, a score of 2 was given if both neuropil borders had at least some stained cells, whereas a score of 1 was given if stained cells were found in only one of these borders (e.g., if the region scored as 
A

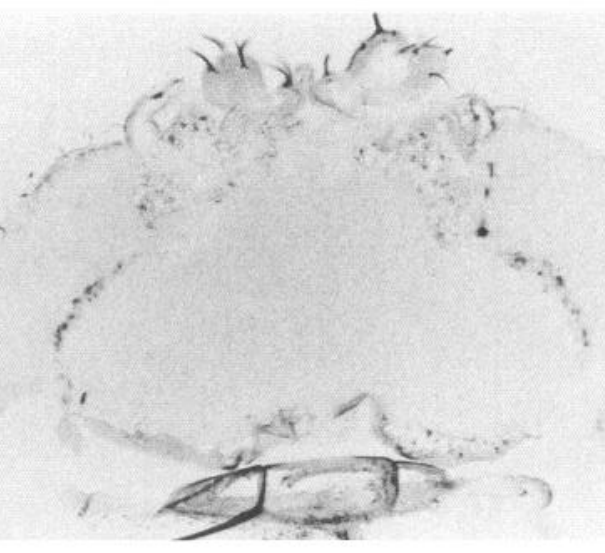

C

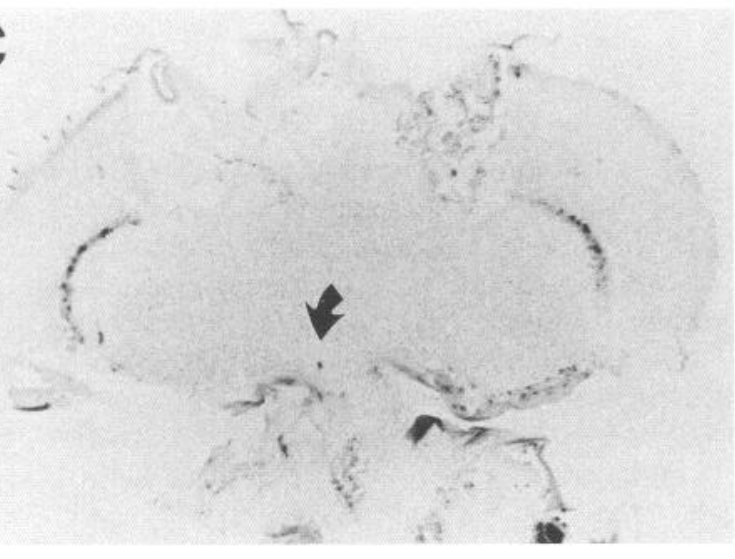

E

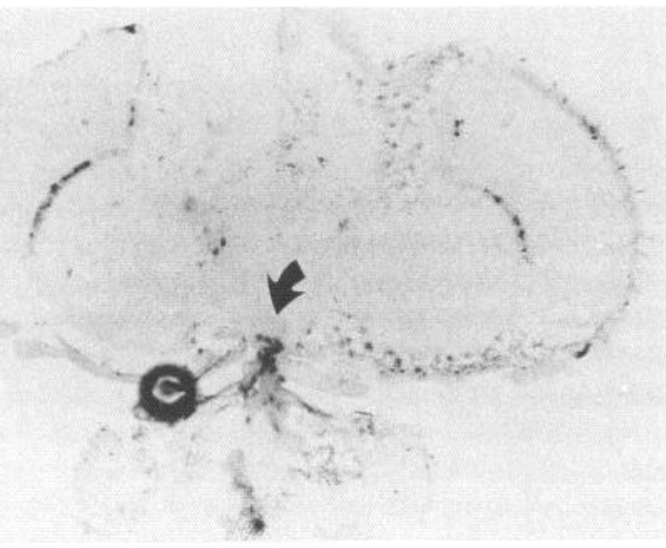

Time of Day (Hrs)

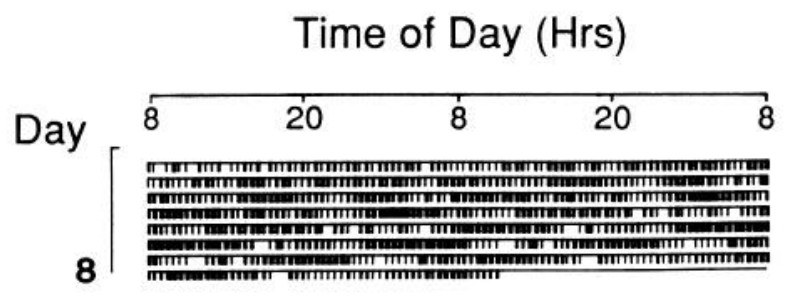

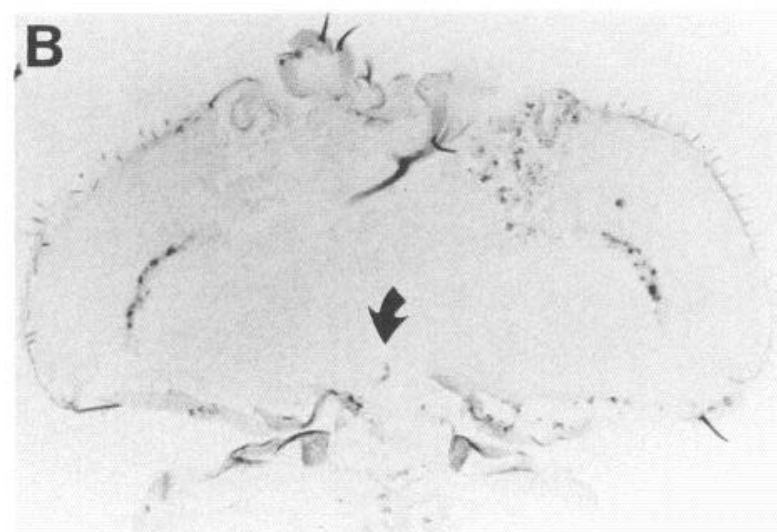
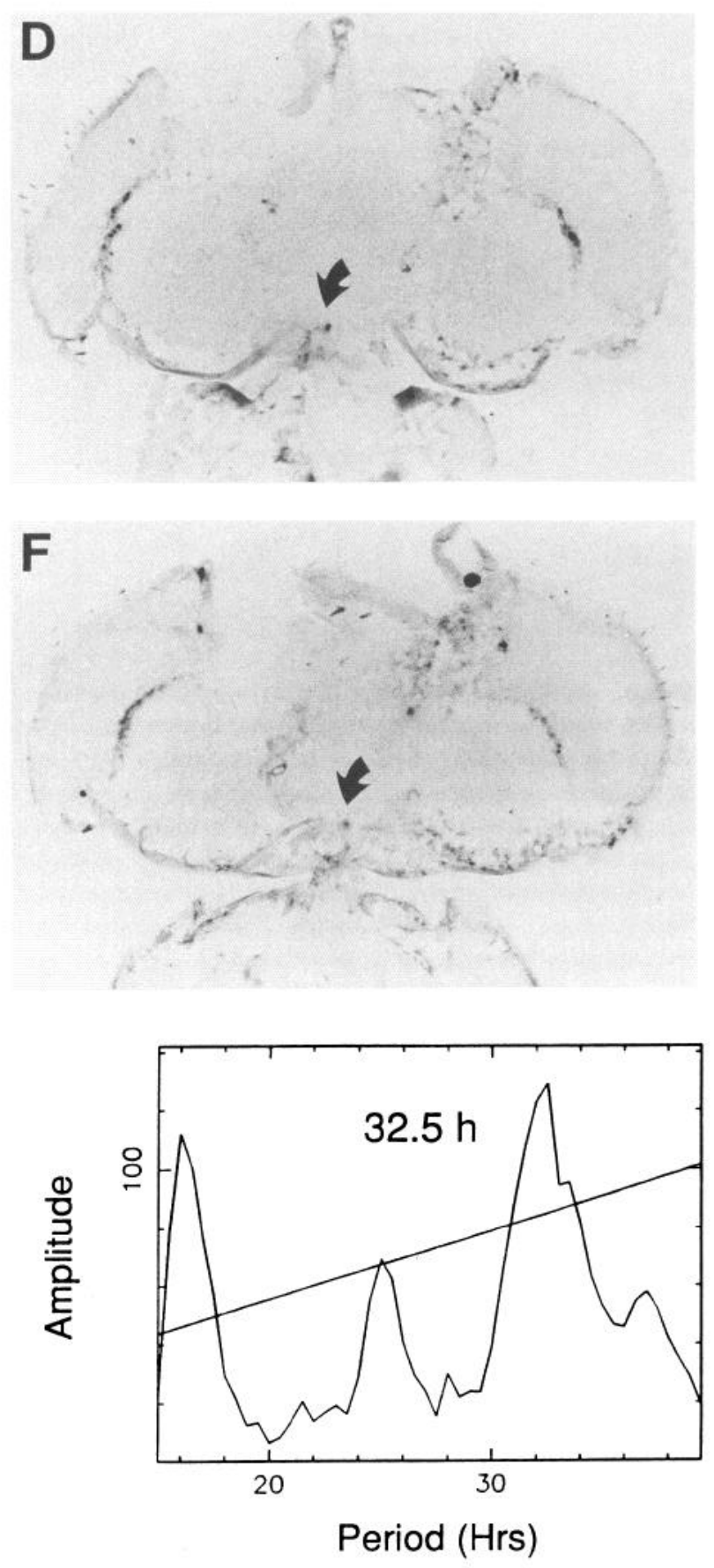


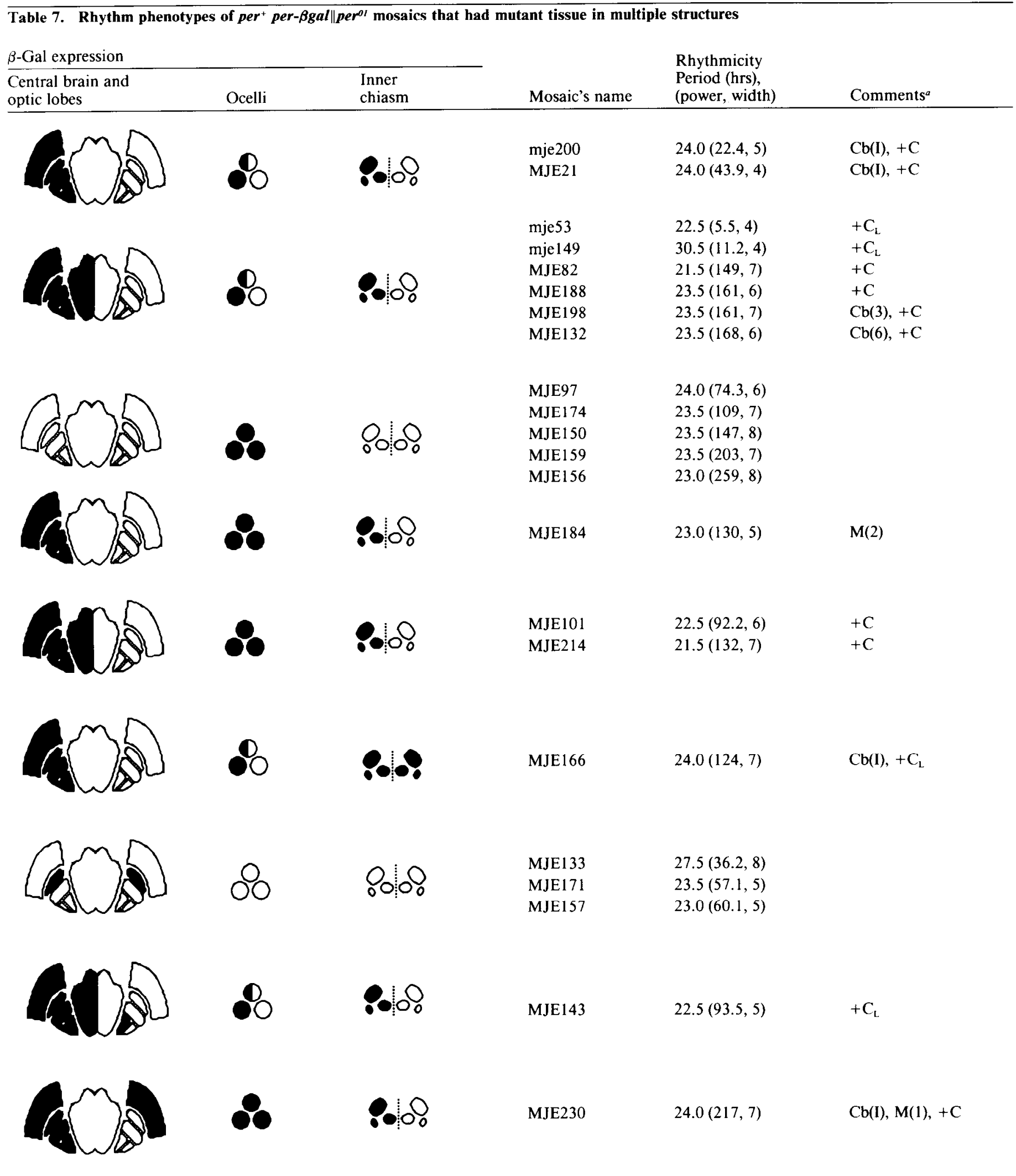

Figure 9. Pattern of per-driven $\beta$-galactosidase expression $(A-F)$, actogram (lower left), and periodogram (lower right) of per ${ }^{+}$per- $\beta g a l l \mid p e r^{\circ /}$ mosaic MJE6. $A-F$ show a dorsal-to-ventral series of consecutive sections that contained the entirety of the per-expressing tissue found in this animal's head. These sections all belonged to the subesophageal region of the brain. Note that most of the per-driven $\beta$-galactosidase expression is confined to a small patch of tissue (arrows). 
Table 7. Continued

$\beta$-Gal expression

Central brain and optic lobes
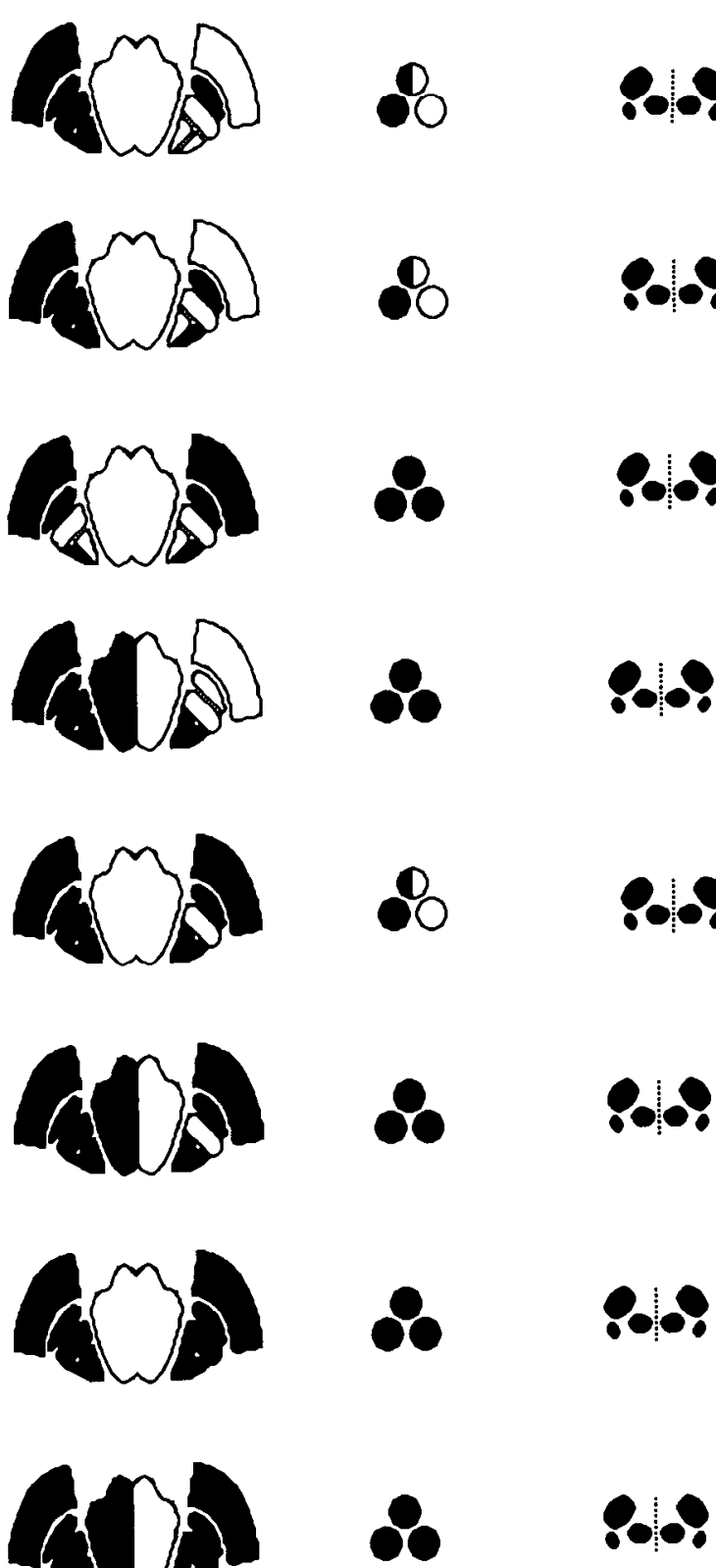

Rhythmicity

Period (hrs) (power, width)

Comments $^{a}$

MJE94

$23.0(126,11)$

$\mathrm{M}(1), \mathrm{Ic}(1)$

MJE124

$24.0(107,7)$

$\mathrm{M}(2),+\mathrm{C}_{\mathrm{L}}$

mje235

$26.0(31.9,5)$

mjel 42

$24.5(36.4,4)$

$+\mathrm{C}_{\mathrm{t}}$

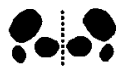

MJE162

$35.5(51.7,4)$

$\mathrm{Lo}(1), \mathrm{Lp}(1),+\mathrm{C}_{\mathrm{L}}$

MJE185

$26.5(47.6,4)$

$\operatorname{Lo}(1), \operatorname{Lp}(1),+C_{L}$

MJE226

$34.5(29.8,7)$

$\mathrm{Cb}\left(\mathrm{B}_{\mathrm{L}}\right), \mathrm{Lp}(1)$

MJE229

MJE6
$37.5(43.9,11)$

$32.5(44.2,6)$
$\mathrm{Cb}(4), \operatorname{Lo}(1)$

$\mathrm{Cb}(1), \mathrm{M}(1), \mathrm{Cb}\left(\mathrm{C}_{\mathrm{L}}\right)$

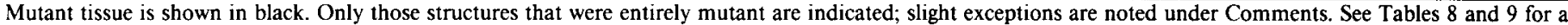

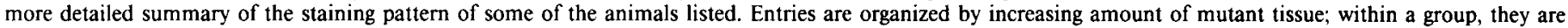
organized by ascending power values. The names of animals expressing weak rhythmicities (see Results) are in lower case.

Abbreviations and format are as in Tables 5 and 6 .

"medulla inner" was null but the relevant region of the central brain did have stained cells). Finally, a score of 0 was given if neither of these borders (as well as the areas between them) showed staining. Scores were given starting at the first section in which this area could be visualized (which was either the section at which the medulla was first visible or the following one), down to and including the second subesophageal section. We have found these to be conservative boundaries for the distribution of these cells. Thus, approximately eight sections in the supraesophageal and two sections in the subesophageal ganglion were scored for staining in this region [giving scores of $(8 \times 2)+(2 \times 2)=20$ per half head in a nonmosaic animal].

From this more detailed scoring, "profiles" of staining were constructed, which showed, for each structure, the percentage of control expression that was found at each level (not shown). These results have been summarized in Tables 8 and 9 by in- 
dicating the total number of cells present in the right, left, and right plus left sides in the supra- and subesophageal halves of each structure as percentage of wild-type staining.

Rhythmic mosaics showing the least per expression. The results shown in Tables 8 and 9 summarize the staining and rhythm phenotypes of those rhythmic mosaics that had the largest patches of mutant tissue. They reveal that the number of per-expressing cells that are sufficient for rhythmicity can be very small relative to the total number of these cells that are seen in control animals. Indeed, many of the animals listed in these tables either were null or had less than $\sim 10 \%$ of the normal number of cells stained in most of the brain. An exception to this is the ventral brain, for which the number of per $^{+}$-expressing cells could be similar to that found in nonmosaic control animals. For instance, some sections of MJE6 (compare Fig. 9) had 100\% of the number of cells that are normally stained in this region. Nevertheless, in absolute terms, this percentage does not amount to many cells (Tables 8,9 ).

\section{Does circadian rhythmic behavior have a discrete focus (or} foci)?

Superimposing the different profiles of staining obtained in the exceptional mosaics did not reveal an area that was always stained in these rhythmic animals. The only candidate for such a region is the ventral brain, which is stained in most of these animals. However, even there, some animals showed very little staining (e.g., MJE 230; see Fig. 12). Thus, we were unable to pinpoint a discrete focus (or foci), and can only conclude that expression in the ventral brain appears to be sufficient for rhythmicity.

Rhythmicity and per expression in the "lateral neurons." We believe that the results obtained in mosaic animals makes it unlikely that per expression in thesc cclls is csscntial for rhythmicity, although it may be required for normal rhythmicities (see Discussion). The strongest evidence in this regard is the fact that some of the rhythmic mosaics (e.g., MJE229, MJE6, and MJE185; see Table 9) showed, bilaterally, no staining in any of the locations at which these cells are usually found. In addition, if per expression in these cells were essential (which would imply that some of them expressed per and were missed in the scoring of the three mosaics listed above), one would expect animals that are bilaterally null at these locations to be overrepresented among the arrhythmic animals. However, this was not the case. Thus, out of 59 arrhythmic animals that had patches of mutant tissue at this location, 5 showed staining in this region in very few ( 3 or 4 , considering both sides of the head) sections, and 7 were bilaterally null (of these 7,6 were almost entirely mutant in the rest of the head). In contrast, out of 36 rhythmic animals that had mutant tissuc that included the "Brain/medulla" region, 5 had few stained sections and 7

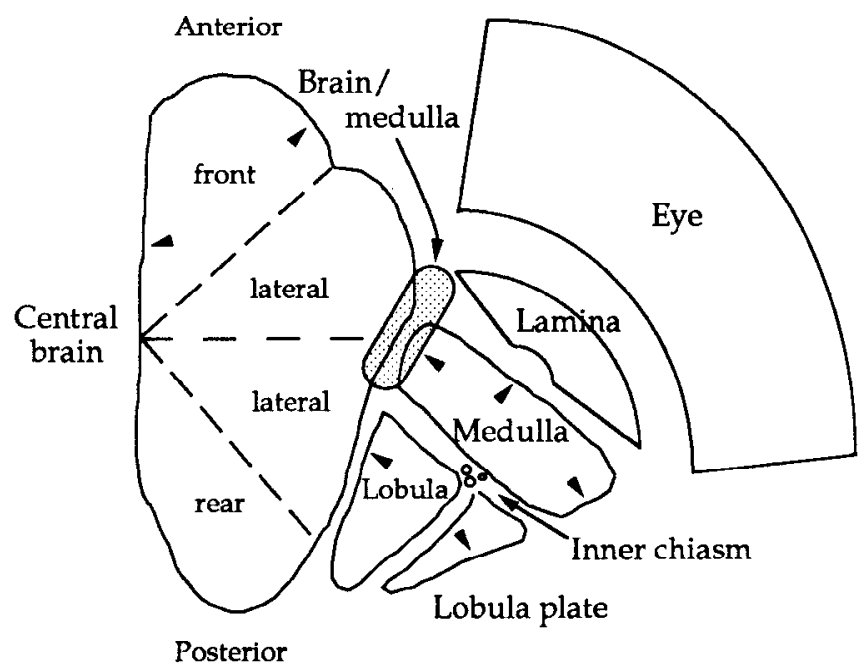

Figure 10. Diagram of the areas of the brain that were scored in the mosaics. Arrowheads indicate the regions that express per-driven $\beta$-galactosidase in per $^{+}$per- $\beta$ gal/perol flies; they were scored separately in the detailed scoring of exceptional mosaics (see Results). See text for the definition of the Brain/medulla area.

(the ones listed above) were entirely null. Thus, the proportion of these "brain/medulla" null animals was similar for both groups.

Could the focus for this behavior be a diffuse one? An alternative possibility is that this behavior does not have a discrete focus (or foci), but that instead it is only the number of cells that express per that determines an animal's rhythm phenotype. This interpretation is suggested by the impression that, except for the LNs, the other per-expressing cells in the optic lobes and the brain could all belong to the same class of cells. Thus, most of them occur at similar types of locations (e.g., at the boundaries of cortex and neuropil) and appear to share the few properties that we examined (e.g., similar morphology and lack of elav immunoreactivity). Thus, they may all belong to a single functional group of cells. If this were the case, it is conceivable that per expression in a certain number of them would be sufficient for rhythmicity to be manifest, regardless of their location.

A "diffuse" focus is consistent with the results obtained in mosaic animals. In Figure 11, the percentage of control expression found in the brain, brain/medulla, and the medulla of the exceptional mosaics has been plotted. In these graphs, the values for the supraesophageal and the subesophageal ganglion, and for the total brain (i.e., for the supraesophageal plus subesophageal ganglia) have been plotted separately. The mosaics have becn ordered by ascending power values. Thus, these percentages for animals expressing rhythms with the lowest powers are

Table 8. Average number of cells expressing the per- $\beta$-galactosidase fusion gene in half a head of a nonmosaic (control) animal

\begin{tabular}{|c|c|c|c|c|c|c|c|c|c|}
\hline & Brain & $\mathrm{Br} / \mathrm{Med}$ & Medulla & Lamina & Lobula & L. plate & In. Ch. & Fyes & Ocelli \\
\hline Sup. & $288 \pm 28$ & 16 & $122 \pm 12$ & 100 & $22 \pm 2.7$ & $26 \pm 2.9$ & $20 \pm 1.9$ & 100 & 100 \\
\hline Sub. & $65 \pm 6.9$ & 4 & $94 \pm 10$ & 100 & $11 \pm 1.8$ & $14 \pm 2.0$ & $14 \pm 1.6$ & 100 & - \\
\hline Total & $353 \pm 35$ & 20 & $216 \pm 22$ & 100 & $33 \pm 4.5$ & $40 \pm 4.9$ & $34 \pm 3.5$ & 100 & 100 \\
\hline
\end{tabular}

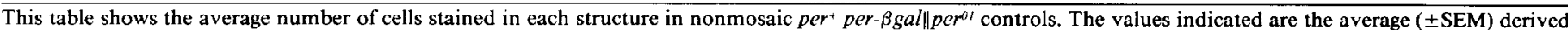

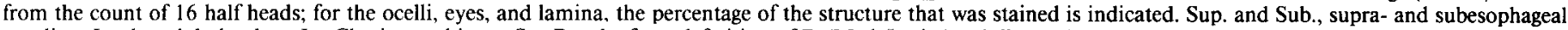
ganglion; L. plate, lobula plate; In. Ch., inner chiasm. See Results for a definition of $\mathrm{Br} / \mathrm{Med}$ (brain $/ \mathrm{medulla}$ area). 


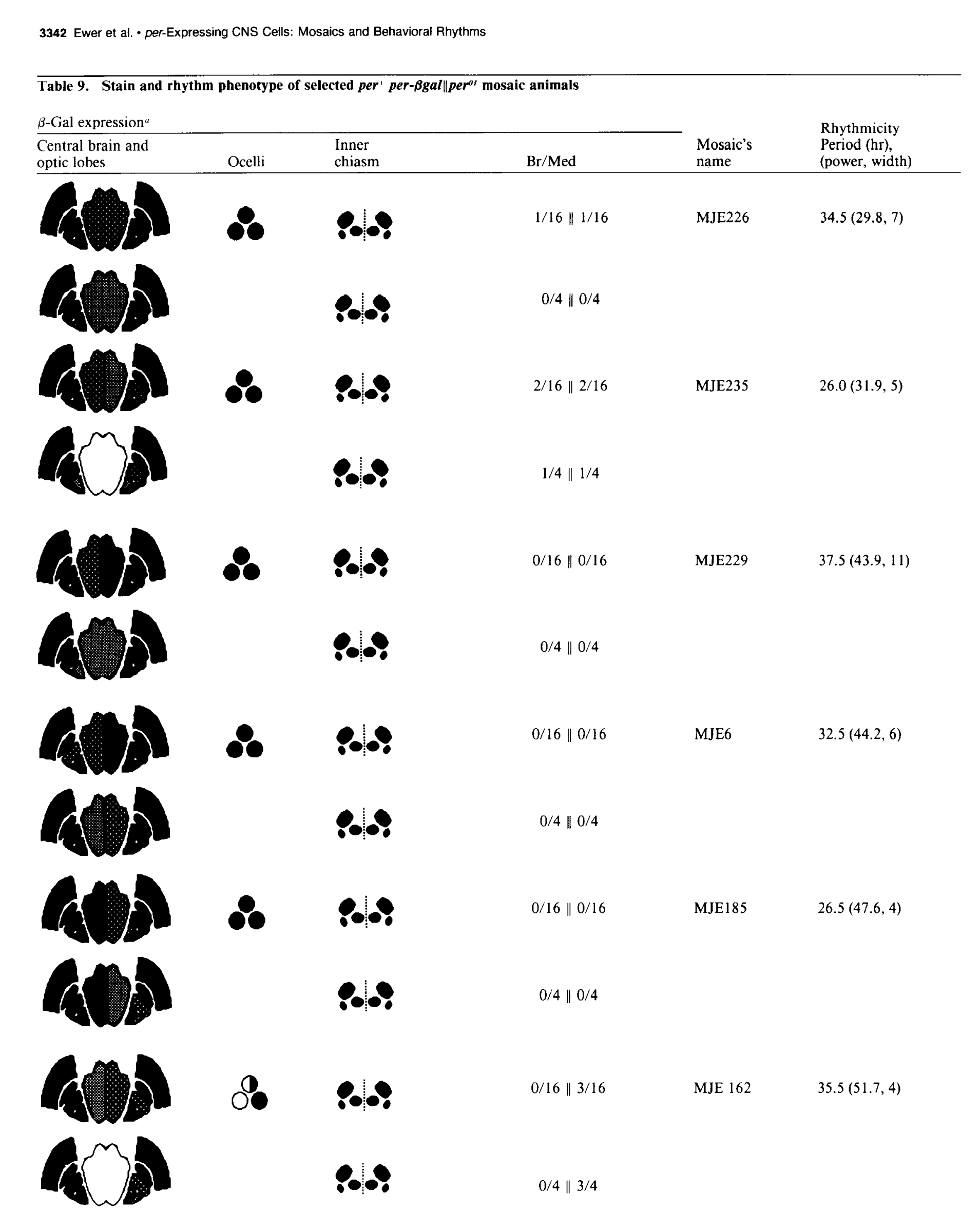





\section{1- Supraesophagea}

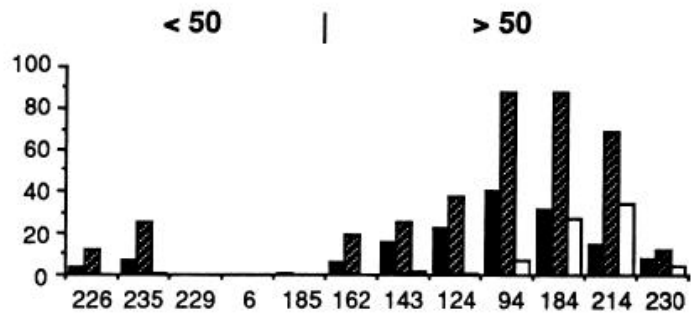

\section{2- Subesophageal}

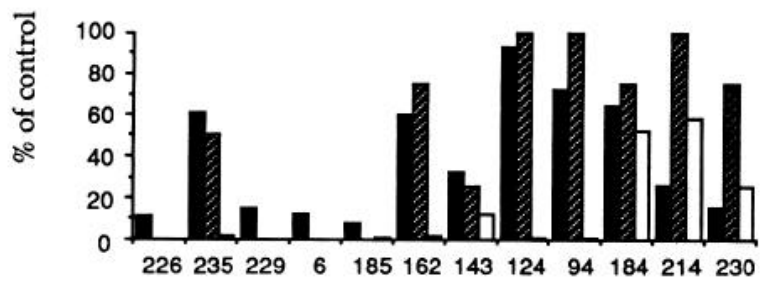

3- Total

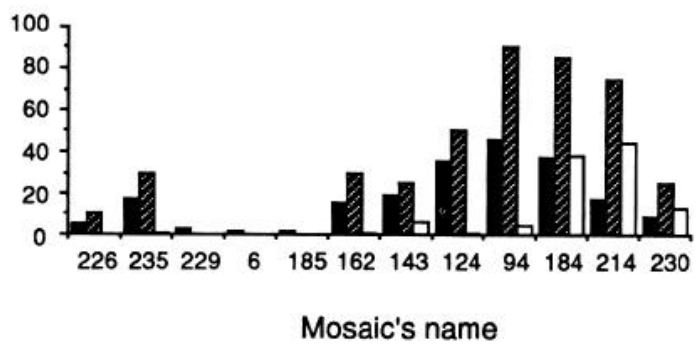

Brain/medulla
Medulla

Figure 11. Histogram of the percentage of control stain seen in the per $^{+}$per- $\beta$ gal $\|$ perol mosaics that were scored in detail, in the supraesophageal (1), subesophageal (2), and supraesophageal plus subesophageal regions $(3$; total) for the central brain, brain $/ \mathrm{medulla}$, and medulla. Mosaics have been ordered in ascending power values (those with powers greater than 50 are to the right of the bar indicated at the top).

graphed to the left of those whose rhythms had larger power values.

As expected, these graphs show that some of these animals had no expression in the medulla and the brain/medulla. In addition, they show that animals that expressed rhythms with powers greater than 50 tended to show more staining than those with powers that were less than 50 . Note also that the outline of these graphs is smoother for the data corresponding to the supraesophageal ganglion than it is for those of the subesophageal ganglion, and tends to increase monotonically from left to right. This suggests that animals with greater number of cells in the supraesophageal ganglion tended to express stronger rhythmicities, or that animals with more cells in the supraesophageal ganglion also tended to have more cells stained in the rest of the brain. There are, however, exceptions to this trend. This might be expected, if only because the power of the rhythms obtained in mosaic animals clearly did not depend only

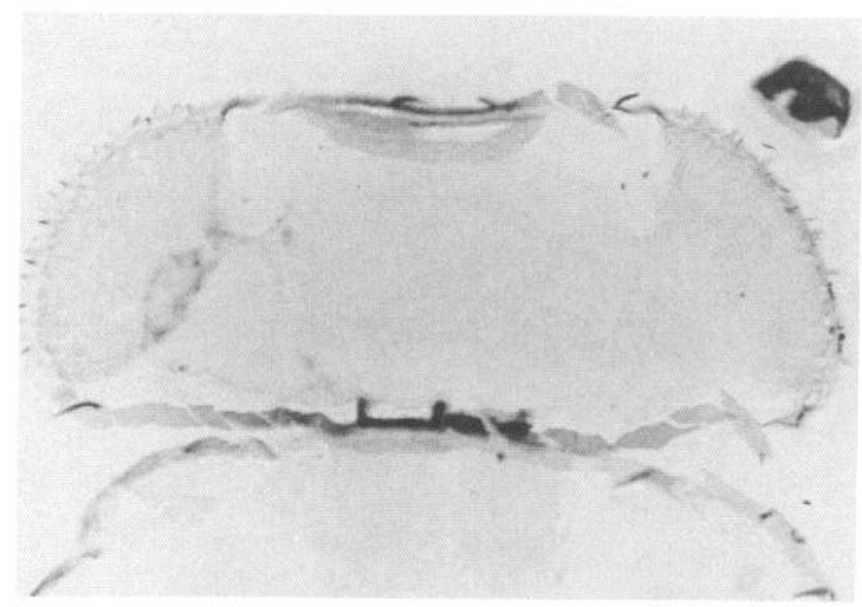

\section{Time of Day (Hrs)}
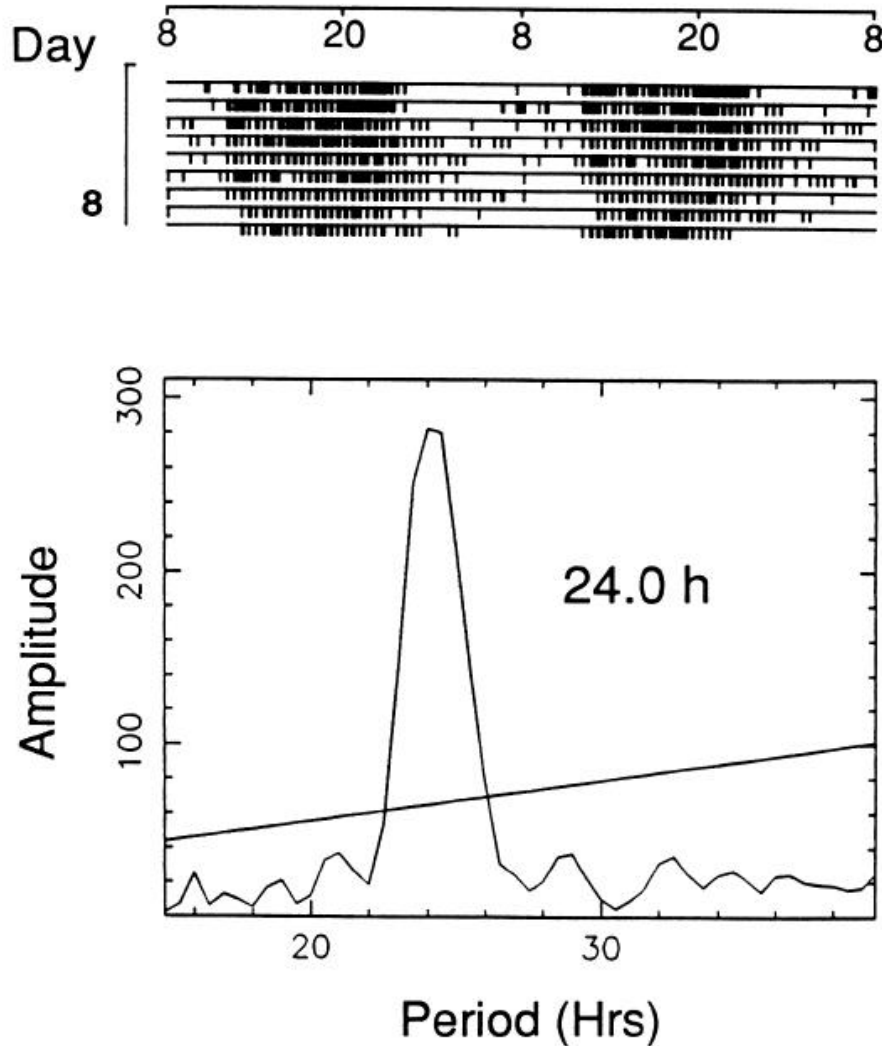

Figure 12. Pattern of per-driven $\beta$-galactosidase expression (top), actogram (middle), and periodogram (bottom) of per ${ }^{+}$per- $\beta g a l \| p e r^{0 I}$ mosaic MJE230.

on the amount of per-expressing tissue. Thus, for instance, it cannot account for the weaker rhythmicity of MJE235 relative to MJE6. Some of the exceptions may, however, be informative. One of these is MJE230. As shown in Figure 12, this animal had a strong $24.0 \mathrm{hr}$ rhythm, yet Figure 11 shows that this fly had very little per expression in the structures that were considered. Nevertheless, as shown in Table 9, this animal had some staining in all of the other regions of the brain excepting the eyes and the ocelli. Thus, it could be that this animal man- 


\begin{tabular}{|c|c|c|c|c|c|c|c|c|}
\hline Genotype & $N$ & $N_{\text {AR }}$ & $N_{\mathrm{RW}}$ & $N_{\mathrm{R}}$ & $\% R$ & $\begin{array}{l}\text { Period } \\
(\mathrm{hr} \pm \mathrm{SEM})\end{array}$ & $\begin{array}{l}\text { Power } \\
( \pm \text { SEM })\end{array}$ & $\begin{array}{l}\text { Width } \\
( \pm \text { SEM })\end{array}$ \\
\hline \multicolumn{9}{|l|}{ 1. per $^{+}$per- $\beta$ gal/per $;$ pal ${ }^{+}$} \\
\hline $\mathrm{pal}$ from $\mathrm{pal} / \mathrm{pal}$ father & 34 & 8 & 2 & 24 & 71 & $23.6 \pm 0.08$ & $152 \pm 13$ & $6.6 \pm 0.2$ \\
\hline $\mathrm{pal}$ from $\mathrm{pal} / \mathrm{CyO}$ mother & 24 & 5 & 0 & 19 & 79 & $23.5 \pm 0.09$ & $165 \pm 13$ & $6.7 \pm 0.2$ \\
\hline 3. per $^{+}$cho $s n / Y ; 0 / I V$ & 4 & 3 & 1 & 0 & 0 & - & - & - \\
\hline per $^{+}$cho $s n / Y ; I V / I V$ (siblings) & 13 & 0 & 0 & 13 & 100 & $24.2 \pm 0.07$ & $198 \pm 9.2$ & $7.9 \pm 0.2$ \\
\hline per $^{+}$cho $s n / Y$ & 9 & 0 & 0 & 9 & 100 & $23.8 \pm 0.1$ & $169 \pm 23$ & $7.3 \pm 0.5$ \\
\hline per $^{+}$cho $s n / Y$ (pooled) & 22 & 0 & 0 & 22 & 100 & $24.0 \pm 0.07$ & $186 \pm 11$ & $7.7 \pm 0.2$ \\
\hline 4. per $^{+} /$per $^{+} ;$pal/ + mosaic & 50 & 5 & 5 & 40 & 80 & $24.2 \pm 0.1$ & $166 \pm 12$ & $6.7 \pm 0.2$ \\
\hline
\end{tabular}

For abbreviations, see Table I notes.

ifested a strong rhythm because it had appreciable per expression in parts of the brain other than the central brain.

\section{Possible etiologies of the arrhythmicity of control mosaics}

As shown in Table 4, about one-third of control mosaics expressed an arrhythmic phenotype. This is a much higher proportion than that seen in the wild-type strains that we have tested (see Table 10; Hamblen et al., 1986; Dushay et al., 1989; Hamblen-Coyle et al., 1989; Ewer et al., 1990; Liu et al., 1991), and in the nonmosaic animals of this genotype (compare Table 10). This proportion of arrhythmicity is similar to that reported by Konopka et al. (1983) in per $^{+} \|$pers mosaics.

Heterozygosity for the pal mutation. In order to determine whether this arrhythmicity was due to heterozygosity for the pal mutation per se, we determined the rhythm phenotype of (nonmosaic) $\mathrm{per}^{+}$per- $\beta$ gal/per ${ }^{+}$animals that were heterozygous for the pal mutation, in which the pal-bearing chromosome was either derived from a homozygous pal father, or from a heterozygous $\mathrm{pal}^{\mathrm{pal}} \mathrm{pl}^{+}$mother. As shown in Table 10, arrhythmicity was obtained among all pal-bearing progeny, regardless of the origin of the pal chromosome. However, the presence of the pal mutation per se does not account for the entirety of the arrhythmicity found among control mosaics. In addition, it cannot be the cause of the arrhythmicity of the $p e r^{+} \| p e r s$ mosaics that were generated by Konopka et al. (1983) using a mitotically unstable ring-X chromosome.

Heterozygosity for autosomes. The easiest to investigate of the effects on rhythmicity due to the loss of an autosome are those that result from the loss of the fourth chromosome. As shown in Table 10, a high fraction of (completely) haplo-4 animals were arrhythmic. An animal in which somatic loss of the fourth chromosome had occurred would be expected to bear anatomical abnormalities, due to the growth disadvantage of the patch of Minute/ + tissue relative to that of the $+/+$ tissue (Morata and Ripoll, 1975). A candidate Minute mosaic is shown in Figure 13. The section shown in this figure is from the same animal as that shown in Figure 12, and is that of a strongly rhythmic animal. Thus, in spite of its structural abnormalities, this animal expressed a robust $24 \mathrm{hr}$ rhythm.
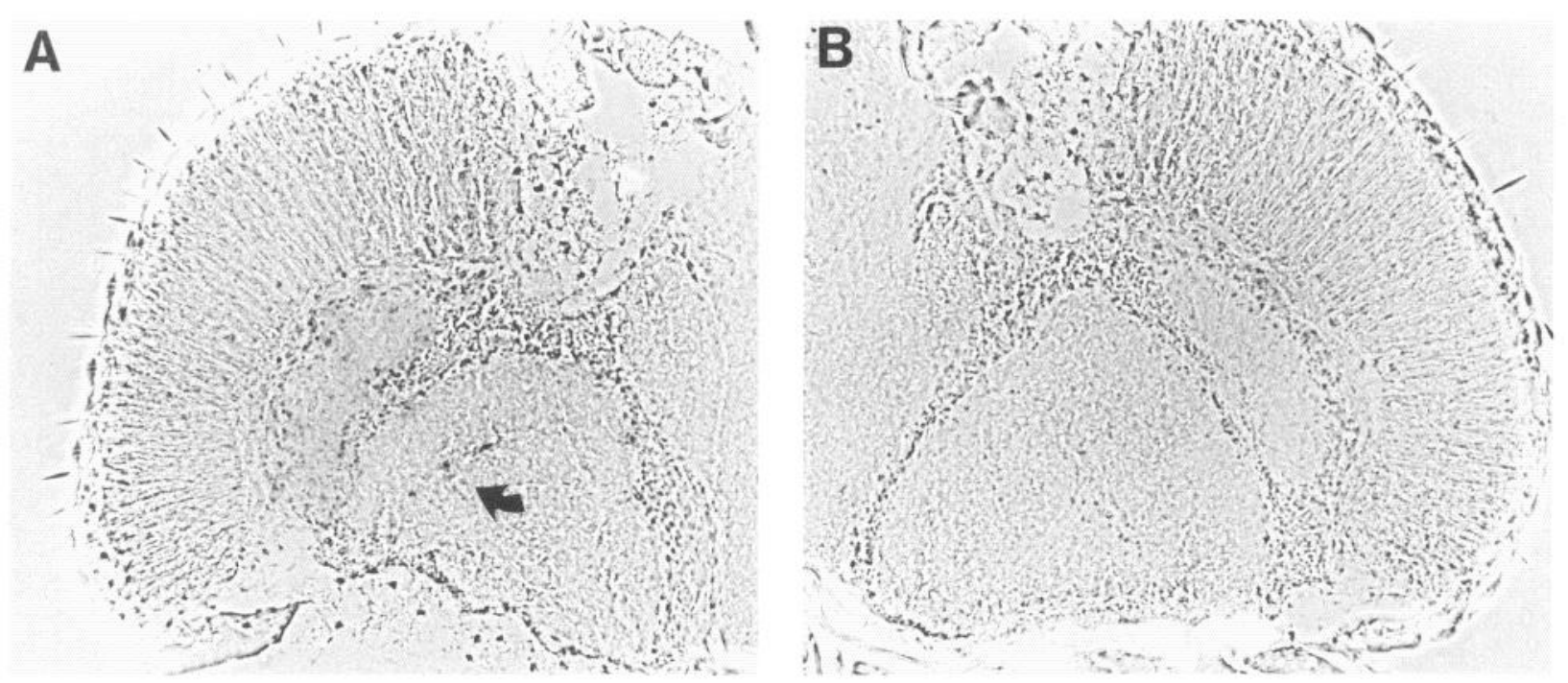

Figure 13. Horizontal section of a per ${ }^{+}$per- $\beta g a l \| p e r^{o l}$ mosaic that may also be a Minute mosaic. This animal (MJE230) shows evident structural abnormalities in the optic lobes of the left side $(A$, arrow $)$. Note that the outer cortex of the lamina is smaller than that seen on the contralateral side, while the inner one seems larger; likewise, the second optic chiasm is ill defined, as is the border between the lobula and the lobula plate. Finally, the cells that are usually located within the second optic chiasm are not clustered, and seem to be within the neuropil of the medulla. See Figure 12 and Tables 5-7 for a summary of this animal's rhythm phenotype. 
Imbalance of per expression in neighboring cells of a mosaic. The arrhythmicity that is due to mosaicism per se might be caused by an imbalance in per expression among the two different classes of cells that are present in a mosaic. In all the "test" per mosaics made to date (Konopka et al., 1983; present results; Hamblen-Coyle, unpublished observations), the patch of haplo- $X$ tissue has expressed a different per allele than that expressed by the diplo-X one. [In the case of the present study, the diplo- $X$ cells express the product of the per- $\beta$ gal fusion gene, in addition to the wild-type per protein, which is expressed by both types of cells. Since this fusion gene contains some of the per coding sequences, its expression could influence the expression of the normal per gene (cf. Hardin et al., 1990; Zerr et al., 1990). Evidence for an influence of the per- $\beta$ gal fusion gene prod-

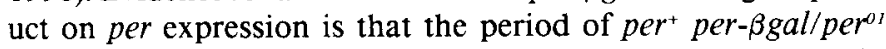
flies is shorter than that of $p e r^{+} /$perol $^{\circ}$ flies. Indeed, as shown in Tables 1 and 2, per $^{+}$per- $\beta g a l / p e r^{\prime \prime}$ flies had an average period of $23.6 \pm 0.1 \mathrm{hr}$. In contrast, $\mathrm{per}^{+} / \mathrm{per}^{\prime \prime \prime}$ flies express longer periodicities, usually about $24.9 \mathrm{hr}$ (Smith and Konopka, 1981; Citri et al., 1987; Hamblen-Coyle et al., 1989).]

In order to test this hypothesis, we generated mosaics that were internally unmarked and were simply $\mathrm{per}^{+}$in all tissues. Since all of the cells of such mosaics are of the same genotype, these animals should have all been rhythmic if "imbalance" of per expression were the cause of the arrhythmicity in the mosaics discussed previously. However, as summarized in Table 10, a much higher than normal proportion (14 of 40) of such animals was arrhythmic or weakly rhythmic.

In summary, the arrhythmicity that is caused by mosaicism appears to be due to a combination of many factors, and could not be entirely accounted for by any of the ones that we tested.

\section{Discussion}

Strong circumstantial evidence accumulated over the last 20 years, and more recently obtained direct evidence, strongly suggests that the per gene of $D$. melanogaster is critical to circadian pacemaker function. Thus, the study of this gene, its expression, and the distribution of its product might provide an entry point to the mechanism that underlies circadian rhythmicity. Of particular neurobiological interest are the cells that express this gene, as they would presumably include the cells in which the per product is required for the generation of these rhythms. In addition, the characterization of the types of cells that express per might provide an insight into the mechanism and/or the pathway by which circadian rhythms are generated in this organism.

We have initiated a detailed characterization of per-expressing cells in the CNS of adult $D$. melanogaster, using wild-type flies as well as germline transformants in which $\beta$-galactosidase serves as a reporter for per expression. Our results have considerably extended previous descriptions (Liu et al., 1988, 1991; Siwicki et al., 1988). Those studies proposed, in part, that the cells that express per in the adult CNS included both neurons and glia. This supposition was based on cell location. Thus, for instance, the large per-immunoreactive cells that occur in the dorsal anterior cortex (lateral cells, or LCs) were thought to be neuronal ("lateral neurons," or LNs; Siwicki et al., 1988). In contrast, most of the other per-expressing cells were thought to be glia (Liu et al., 1988; Siwicki et al., 1988), as they are located at positions where glia have been described in Diptera (Strausfeld, 1976) and other insects (cf. Wigglesworth, 1959; Carlson, 1987; Meyer et al., 1987).
We have approached this question experimentally using an antibody to the neuron-specific product of the elav gene in conjunction with anti- $\beta$-galactosidase on per- $\beta$ gal-bearing transformants, or anti-per antibody on wild-type flies. Our results have confirmed and extended the proposed assignments of the different per-expressing cells to the neuronal and glial classes. Thus, we found that only the LCs, as well as a group of smaller per-immunoreactive cells restricted to the dorsalmost region of the central brain, were elav positive, thus supporting the notion that these cells are neurons. All other per-expressing cells, in contrast, were elav negative, suggesting that they are indeed glial in nature.

We have found cortical per ${ }^{+}$-expressing cells that are elav negative. However, we could not definitively determine the converse, namely, whether all the elav-negative cortical cells express per (which might imply that all cortical glia are per positive). From observations of per immunoreactivity that permitted counting the number of cells present in a given image (Liu et al., 1992), it was estimated that well less than one-half percent of the cells in the cortex express per. This is a much lower percentage than the proportion of cells that are glia in the CNS of insects. In such nervous systems, estimates of 1.5-8 times as many glia as neurons have been quoted (for review, see Carlson and Saint-Marie, 1990). Thus, it is likcly that there are many elav-negative cells that also do not express the period gene.

Given that most neurons in the fly's CNS are not identifiable, it is possible that the elav-negative per-expressing cells belong to a rare, and heretofore unidentified, class of neurons that do not express elav. However, at least in the optic lobes, this possibility is unlikely. Indeed, most of the classes of neurons that have been described there are part of optic cartridges, of which there are the same number as the number of ommatidia. There are too few per-expressing cells for them to correspond to these types of optic lobe neurons (unless they are cells that are present in a subset of cartridges). In addition, the cell bodies of optic lobe neurons seem to be located well within the cortical layer (Strausfeld, 1976; Fischbach and Dittrich, 1989), not at the margins of the neuropil. Nevertheless, most of the cell types that have been described in these reports have been identified using Golgi impregnation. Since this process stains only a very small fraction of cells, infrequent cell types are likely to go unnoticed. So, although we believe this to be unlikely, the possibility remains that the elav-negative $p^{+} r^{+}$cells are neurons.

In insects, the nature of pacemaker cells is unknown. In fact, only in a few cases has the anatomical region that contains a pacemaker been even broadly defined. We have approached this problem using internally marked $p e r^{t} \| p e r^{o t}$ mosaics to determine the locations at which per expression is required for circadian locomotor activity rhythms. Given that per expression appears to be essential to the actual functioning of the pacemaker, the focus of this gene's action should identify the anatomical location of the circadian clock.

Using such mosaics, we have shown that per expression in the central brain is sufficient for locomotor activity rhythmicity of adult $D$. melanogaster, whereas expression in the eyes, the occlli, and any of the optic lobes is not required for this phenotype to be manifest. These results imply that the central brain contains the, or at least a, circadian pacemaker, and that the other brain structures either do not contain a pacemaker or do not contain the only pacemaker that drives the fly's circadian rhythmicity.

Since we did not recover animals that expressed the per- 
reporter fusion only in the optic lobes, we were unable to determine whether expression in the central brain is both sufficient and necessary for rhythmicity.

An unexpected finding of the present study was that a very small patch of per-expressing tissue seemed to be sufficient for rhythmicity to be manifest, albeit weak and of long period. In the few examples that were found of such animals, the patch of per $^{+}$tissue was in the ventral brain, and thus in a region that is devoid of pert-expressing neurons.

A role for glial cells in circadian pacemaker function may be unexpected. However, a number of recent observations provide at least circumstantial evidence that this could be the case. In mammals, the suprachiasmatic nuclei (SCN) of the hypothalamus, which contains the main circadian pacemaker in this organism (e.g., Meijer and Rietveld, 1989; Ralph et al., 1990), can be specifically delineated using an antibody to a vertebrate glial maker (glia fibrillary acidic protein; Morin et al., 1989). In addition, SCN astrocytes exhibit ultradian oscillations of calcium concentration (as do neurons). These oscillations, which may underlie circadian pacemaker function, can be influenced by SCN transmitters (van den Pol et al., 1992), some of which are present in astrocytes (van den Pol and Tsujimoto, 1985). In the mollusk Bulla, a screen for antibodies to the eye, which is believed to contain this animal's circadian pacemaker (Jacklet, 1985), produced a monoclonal antibody that recognized an antigen present in the putative pacemaker cells; this antigen exhibited a circadian fluctuation in abundance. In addition to these cells, the antibody also labeled what are believed to be glial processes in the CNS and the eyes (Roberts et al., 1989; Bedian et al., 1991). Our results suggest that glial cells may likewise play a role in pacemaker function in Drosophila. The everincreasing number of tools (c.g., Bier et al., 1989) and markers (e.g., Buchner et al., 1988; Buchner, 1991) that are becoming available in Drosophila for the study of CNS development and structure should allow the nature of per-expressing cells to be further investigated.

While glial expression appears to be sufficient for some rhythmicity to be manifest, per expression in LNs might be required for the manifestation of robust circadian rhythmicity. A separate role for neuronal and glial per expression in the generation of pacemaker activity can be hypothesized based on the rhythmicity and pattern of per expression seen in different transformant strains bearing incomplete per genes. Thus, for instance, transformant flies from the "8.0" strain express weak rhythmicities whose periods are, nonetheless, on average close to $24 \mathrm{hr}$ (Hamblen et al., 1986; Liu et al., 1991). The (inferred) pattern of per expression in these flies shows a nonuniform decrease with respect to wild-type, such that per expression is much lower at most brain locations except in the general vicinity of the LNs (Liu et al., 1991). In contrast, flies from the transformant strain called "CG" show an overall lower level of per expression than wild-type, which is, however, higher than the average level of per expression found in " 8.0 " transformants. Flies from this "CG" strain express stronger rhythmicities than those expressed by " 8.0 " transformants. However, the average period of these rhythms is significantly longer than that of " 8.0 " transformants. These results suggest that robust rhythmicity can be achieved through high overall levels of per expression (which would correspond mostly to glial expression), while wild-type periodicities may require normal levels of per expression in the LNs (cf. Liu et al., 1991).

The mechanism by which the per-expressing neurons and glia might interact to generate circadian rhythmicity is unknown, yet the results obtained in mutants bearing the disconnected (disco) mutation suggest that the role of glial activity might be effected through per-expressing neurons: disco mutants, which are virtually arrhythmic in freerun (Dushay et al., 1989), show apparently normal glial expression, whereas LNs are seen infrequently and tend to be located in ectopic position (Zerr et al., 1990; B. Frisch, unpublished observations; M. Kaneko, personal communication). This suggests that the actual presence of LNs may be required for rhythmicity. In this view, if the LNs were present but were genotypically $p e r^{\circ}$, they might still be influenced by the activity resulting from per $^{+}$-expressing glia, and drive the expression of some behavioral rhythmicity. Such may be the situation obtained in the weakly rhythmic mosaics that apparently showed only per expression in glial cells. Thus, given the potential for electrical coupling between glial cells ( $\mathrm{cf}$. Lane, 1984), their role could be, primarily, to couple the pacemaker activity of the LNs throughout different regions of the CNS. Such a coupling might also be achieved via a humoral pathway (cf. Handler and Konopka, 1979). In contrast to the LNs, the per-expressing neurons located in the dorsalmost cortex of the central brain are present in quasi-wild-type numbers in disco flies. This suggests that the presence of these cells is not sufficient for rhythmicity. Using mosaics, we have shown that per expression in these neurons is probably not required for circadian rhythmicity.

We found that approximately one-third of the control mosaics - flies that are haplo\|diplo-X mosaics, but per' in all tissues-were arrhythmic. Similar levels of arrhythmicity were also obtained by Konopka et al. (1983) in mosaics bearing per alleles that rarely result in the expression of an arrhythmic phenotype. Mosaicism-induced arrhythmicity could also be revealed in the per $^{+} \|$per ${ }^{\prime \prime}$ mosaics used in the present study by finding arrhythmic animals with a patch of mutant tissue that could be included within that found in a particular rhythmic mosaic. In addition to inducing arrhythmicity, we found that mosaicism weakened animal's rhythm phenotype.

We do not know whether the debilitating effects that mosaicism had on locomotor activity rhythms are particular to this phenotype, or whether they would be manifest in other behaviors. Indeed, for the few behaviors that have been analyzed using mosaics (reviewed in Hall, 1978, 1985), the relevant control mosaics were not examined. Nevertheless, reports of anomalous behaviors in (test) mosaics suggest that this may indeed be the case. Thus, for instance, Hall (1979) reported that the courtship of gynandromorphs that behaved as males (i.e., performed the relevant courtship actions, qualitatively) was less vigorous and more variable than that of control (nonmosaic) males.

The confounding effect that mosaicism has on circadian rhythms compels one to be cautious in the interpretation of the results obtained in test mosaics. The weak rhythms expressed by animals that lacked per expression in the LNs were interpreted as evidence that these may be the fly's circadian pacemaker neurons. However, such mosaics had large patches of hemizygous tissue. Based on the results obtained in control mosaics, these animals would be expected to express weak rhythmicities solely due to the extent of haplo- $X$ tissue. Thus, it is conceivable that a patch of per $^{+}$tissue that does not include the LNs may not only be sufficient for some rhythmicity to be manifest; it could, in a nonmosaic, be sufficient for the expression of normal rhythmicities.

It is unlikely that the focus of per's action can be further 
mapped using chromosomc-loss mosaics. An alternative approach may be the transplantation of marked per $^{+}$cells into a per" embryo. Such transplantations have been used successfully to address questions of gene action (Fischbach and Technau, 1984; Lawrence and Johnston, 1984) and cell lineage (Prokop and Technau, 1991). Using this approach, hosts that have received cells from donors bearing the same number of $\mathrm{X}$ chromosomes could be identified. Thus, the problems associated with the presence of haplo- and diplo- $X$ tissue in the same individual would be eliminated. Alternatively, the use of promoter fusions that would restrict per expression to specific cell types could be used. Of particular interest at present would be the generation of fusions between the elav promoter and per's coding region. Indeed, in transformants bearing such fusions per expression would occur in the LNs but not in the per-expressing glial cells. We have previously shown that indiscriminate per expression has no gross deleterious effects (Ewer et al., 1990). This approach should become increasingly useful, as the number of cloned genes showing specific patterns of CNS expression (e.g., Buchner et al., 1988; Bier et al., 1989; Buchner, 1991) increases.

The results obtained in mosaics show that per expression is not required for rhythmicity in all the cells that express this gene product. per expression at these other locations may reflect a requirement for per in the other processes in which this gene may be involved (see Hall and Kyriacou, 1990, for review). Alternatively, it could be that this gene product has a more widespread expression than what is strictly required for the expression of a wild-type phenotype. A broader-than-essential distribution of a gene's product may be quite common in this and other organisms. Thus, for instance, in Drosophila, the product of the sevenless gene (for review, see Tomlinson, 1988) has becn shown to be only required in photoreceptor R7, yet the expression of this gene is not restricted to this photoreceptor type. In fact, this gene is even expressed in the adult brain (Banerjee et al., 1987). Likewise, Greenspan et al. (1980) found from mosaic experiments that the product of the Acetylcholinesterase $(A C e)$ gene was required for viability in only a small subset of the locations where this gene is expressed. A caveat to this statement is that the product of such genes may play different roles in different tissues or cell types. This is certainly the case for Ace. Indeed, while a small patch of Ace-null tissue was usually compatible with viability, the neuropil associated with such a patch was always morphologically abnormal. Thus, Ace function is essential for viability at only a few locations but is, nevertheless, needed at many more locations for normal morphology. A similar situation also obtains in mammals. Ihus, for instance, whereas the murine proto-oncogene $W n t(1)$ is quite broadly distributed in the developing CNS, its targeted disruption results in severe abnormalities that are confined to the midhrain and cerebellum (McMahon and Bradley, 1990; Thomas and Capecchi, 1990).

\section{References}

Baker BS (1975) paternal loss (pal): a meiotic mutant of Drosophila melanogaster causing loss of paternal chromosomes. Genetics 80 : 267-296.

Banterjee U, Renfranz PJ, Pollock JA (1987) Molecular characterization and expression of sevenless, a gene involved in neuronal pattern formation in the Drosophila eye. Cell 49:281-291.

Bargiello TA, Young MW (1984) Molecular genetics of a biological clock in Drosophila. Proc Natl Acad Sci USA 81:2142-2146.
Bcdian V, Chen Y, Roberts MII (1991) Monoclonal antibodies recognize localized antigens in the eye and central nervous system of the marine snail Bulla gouldiana. J Histochem Cytochem 39:311-319.

Bier E, Ackerman L, Barbel S, Jan LY, Jan YN (1988) Identification and characterization of a neuron-specific nuclear antigen in Drosophila. Science 240:913-916.

Bier E, Vaessin H, Shepherd S, Lee K, McCall K, Barbel S, Ackerman L, Carretto R, Uemura T, Grell E, Jan LY, Jan YN (1989) Searching for pattern and mutation in the Drosophila genome with a P-lacZ vector. Genes Dev 3:1273-1287.

Buchner E (1991) Genes expressed in the adult brain of Drosophila and the effects of their mutations on behavior: a survey of transmitter and second messenger-related genes. J Neurogenet 7:153-192.

Buchner E, Bader R, Buchner S, Cox J, Emson PC, Flory E, Heizmann CW, Hemm S, Hofbauer A, Oertel WH (1988) Cell-specific immuno-probes for the brain of normal and mutant Drosophila melanogaster. I. Wildtype visual system. Cell Tissue Res 253:357-370.

Campos-Ortega JA, Strausfeld NJ (1973) Synaptic connections of intrinsic cells and basket arborizations in the external plexiform layer of the fly's eye. Brain Res 59:119-136.

Carlson SD (1987) Ultrastructure of the arthropod neuroglia and neuropil. In: Arthropod brain. Its evolution, development, structure and functions (Gupta AP, ed), pp 323-346. New York: Wiley.

Carlson SD, Saint-Marie RL (1990) Structure and function of insect glia. Annu Rev Entomol 35:597-621.

Chiba Y, Tomioka K (1987) Insect circadian activity with special reference to the localization of the pacemaker. Zool Sci 4:945-954.

Citri Y, Colot HV, Jacquier AC, Yu Q, Hall JC, Rosbash M (1987) A family of unusually spliced biologically active transcripts encoded by a Drosophila clock gene. Nature 326:42-47.

Doe CQ, Hiromi Y, Gehring W, Goodman CS (1988) Expression and function of the segmentation gene fushi tarazu during Drosophila neurogenesis. Science 239:170-175.

Dowse HB, Ringo JM (1989) The search for hidden periodicities in biological time series revisited. J Theor Biol 139:487-515.

Dushay MS, Rosbash M, Hall JC (1989) The disconnected visual mutations in Drosophila melanngaster drastically disrupt circadian rhythms. J Biol Rhythms 4:1-27.

Ewer J, Hamblen-Coyle M, Rosbash M, Hall JC (1990) Requirement for period gene expression in the adult and not during development for locomotor activity rhythms of imaginal Drosophila melanogaster. J Neurogenet 7:31-73.

Fischbach KF, Dittrich APM (1989) The optic lobe of Drosophila melanogaster. I. A Golgi analysis of wild-type structure. Cell Tissue Res 258:441-475.

Fischbach KF, Technau G (1984) Cell degeneration in the developing optic lobes of the sine occulis and small-optic-lobes mutants of Drosophila melanogaster. Dev Biol 104:219-239.

Greenspan R, Finn J, Hall JC (1980) Acetylcholinesterase mutants in Drosophila and their effects on the structure and function of the central nervous system. J Comp Neurol 189:741-774.

Hall JC (1978) Behavioral analysis in Drosophila mosaics. In: Genetic mosaics and cell differentiation (Gehring WJ, ed), pp 259-305. Berlin: Springer.

Hall JC (1979) Control of male reproductive behavior by the central nervous system of Drosophila: dissection of a courtship pathway by genetic mosaics. Genetics 92:437-457.

Hall JC (1985) Neural and developmental implications of the genetic and molecular analysis of behavior. In: Molecular bases of neural development (Edelman GM, Gall WE, Cowan WM, eds), pp 565587. New York: Wiley.

Hall JC (1990) Genetics of circadian rhythms. Annu Rev Genet 24: $659-697$.

Hall JC, Kyriacou CP (1990) Genetics of biological rhythms in Drosophila. Adv Insect Physiol 22:221-298.

Hall JC, Gelbart WM, Kankel DR (1976) Mosaic systems. In: Genetics and biology of Drosophila. Vol la (Ashburner M, Novitski E, eds), pp 265-314. London: Academic.

Hamblen M, Zehring WA, Kyriacou CP, Reddy P, Yu Q, Wheeler DA, Zwiebel LJ, Konopka RJ, Rosbash M, Hall JC (1986) Germ-line transformation involving DNA from the period locus in Drosophila melanogaster: overlapping genomic fragments that restore circadian and ultradian rhythmicity to per ${ }^{\prime \prime}$ and per mutants. J Neurogenet 3 : 249-291. 
Hamblen-Coyle M, Konopka RJ, Zwiebel LJ, Colot HV, Dowse HB, Rosbash M, Hall JC (1989) A new mutation at the period locus of Drosophila melanogaster with some novel effects on circadian rhythms. J Neurogenet 5:229-256.

Handler AM, Konopka RJ (1979) Transplantation of a circadian pacemaker in Drosophila. Nature 279:236-238.

Hardin PE, Hall JC, Rosbash M (1990) Feedback of the Drosophila period gene product on circadian cycling of its messenger RNA levels. Nature 343:536-540.

Helfrich C (1986) Role of the optic lobes in the regulation of the locomotor activity rhythm of Drosophila melanogaster: behavioral analysis of neural mutants. J Neurogenet 3:321-343.

Helfrich C, Engelmann W (1983) Circadian rhythm of the locomotor activity on Drosophila melanogaster and its mutants "sine oculis" and "small optic lobes." Physiol Entomol 8:257-272.

Helfrich C, Cymborowski B, Engelmann W (1985) Circadian activity rhythm of the house fly continues after optic tract severance and lobectomy. Chronobiol Int 2:19-32.

Jacklet JW (1985) Neurobiology of circadian rhythm generators. Trends Neurosci 8:69-73.

Jan LY, Jan YN (1982) Antibodies to horseradish peroxidase as specific neuronal markers in Drosophila and in grasshopper embryos. Proc Natl Acad Sci USA 79:2700-2704.

Kankel DR, Hall JC (1976) Fate mapping of nervous system and other internal tissues in genetic mosaics of Drosophila melanogaster. Dev Biol 48:1-24

Kasai M, Chiba Y (1987) Effects of optic lobe ablation on circadian activity in the mosquito, Culex pipiens pallens. Physiol Entomol 12: $59-65$.

Konopka R, Wells S, Lee T (1983) Mosaic analysis of a Drosophila clock mutant. Mol Gen Genet 190:284-288.

Konopka RJ, Benzer S (1971) Clock mutants in Drosophila melanogaster. Proc Natl Acad Sci IISA 68:2112-2116.

Lane NJ (1984) A comparison of the construction of intercellular junctions in the CNS of vertebrates and invertebrates. Trends Neurosci 7:95-99.

Lawrence PA, Johnston P (1984) On the role of the engrailed ${ }^{+}$gene in the internal organs of Drosophila. EMBO J 3:2839-2844.

Lindsley D, Zimm G (1990) The genome of Drosophila melanogaster. Drosophila Info Serv 68.

Lindsley DL, Grell EH (1968) Genetic variations of Drosophila melanogaster. Washington, DC: Carnegie Institute.

Liu X, Lorenz. L, Yu Q, Hall JC, Rosbash M (1988) Spatial and temporal expression of the period gene in Drosophila melanogaster. Genes Dev 2:228-238.

Liu X, Yu Q, Huang Z, Zwiebel LJ, Hall JC, Rosbash M (1991) The strength and periodicity of $D$. melanogaster circadian rhythms arc differentially affected by alterations in period gene expression. Neuron 6:753-766.

Liu X, Zwiebel LJ, Hinton D, Benzer S, Hall JC, Rosbash M (1992) The period gene encodes a predominantly nuclear protein in adult Drosophila. J Neurosci 12:2735-2744.

McMahon AP, Bradley A (1990) The Wnt-l (int-l) proto-oncogene is required for development of a large region of the mouse brain. Cell 62:1073-1085.

Meijer JH, Rietveld WJ (1989) Neurophysiology of the suprachiasmatic circadian pacemaker in rodents. Physiol Rev 69:671-707.

Meyer MR, Reddy GR, Edwards JS (1987) Immunological probes reveal spatial and developmental diversity in insect neuroglia. J Neurosci 7:512-521.

Morata G, Ripoll P (1975) Minutes: mutants of Drosophila autonomously affecting cell division rate. Dev Biol 42:211-221.

Morin LP. Johnson RF, Moore RY (1989) Two brain nuclei con1rolling circadian rhythms are identified by GFAP immunoreactivity in hamsters and rats. Neurosci Lett 99:55-60.

Prokop A, Technau GM (1991) The origin of postembryonic neuro- blasts in the ventral nerve cord of Drosophila melanogaster. Development 111:79-88.

Ralph MR, Foster RG, Davis F, Menaker M (1990) Transplanted suprachiasmatic nucleus determines circadian period. Science 247 : 975-978.

Reddy P, Zehring WA, Wheeler DA, Pirrolta V, Hadfield C, Hall JC, Rosbash MR (1984) Molecular analysis of the period locus in Drosophila melanogaster and identification of a transcript involved in biological rhythms. Cell 38:701-710.

Roberts MH, Chen Y, Bedian V (1989) Temporally varying antigens in the eye of Bulla gouldiana. Soc Neurosci Abstr 15:462.

Robinow S, White K (1988) The locus elav of Drosophila melanogaster is expressed in neurons at all developmental stages. Dev Biol 126: 294303.

Robinow S, White K (1991) Characterization and spatial distribution of the ELAV protein during Drosophila melanogaster development. J Neurobiol 22:443-461.

Rosbash M, Hall JC (1989) The molecular biology of circadian rhythms. Neuron 3:387-398.

Saez L, Young M (1988) In situ localization of the per clock protein during development of Drosophila melanogaster. Mol Cell Biol 8: 5378-5385.

Saint-Marie RL, Carlson D (1983) The fine structure of neuroglia in the lamina ganglionaris of the housefly, Musca domestica L. J Neurocytol 12:213-241.

Siwicki KK, Eastman C, Petersen G, Rosbash M, Hall JC (1988) Antibodies to the period gene product of Drosophila reveal diverse tissue distribution and rhythmic changes in the visual system. Neuron 1: 141-150.

Smith RF, Konopka RJ (1981) Circadian clock phenotypes of chromosome aberrations with a breakpoint at the per locus. Mol Gen Genet 183:243-251

Sokolove PG, Bushnell WN (1978) The chi square periodogram: its utility for analysis of circadian rhythms. $\mathbf{J}$ Theor Biol 72:131-160.

Strausfeld NJ (1976) Atlas of an insect brain. New York: Springer.

Thomas KR, Capechi MR (1990) Targeted disruption of the murine int-1 proto-oncogene resulting in severe abnormalities in midbrain and cerebellar development. Nature 346:847-850.

Tomlinson A (1988) Cellular interactions in the developing Drosophila eye. Development 89:313-331.

Truman JW (1974) Physiology of insect rhythms. IV. Role of the brain in the regulation of the flight rhythm of giant silkmoths. J Comp Physiol 95:281-296.

van den Pol AN, Tsujimoto KL (1985) Neurotransmitters in the hypothalamic suprachiasmatic nucleus: immunocytochemical analysis of 25 neuronal antigens. Neuroscience 15:1049-1086.

van den Pol AN, Finkbeiner SM, Cornell-Bell AH (1992) Calcium excitability and oscillations in suprachiasmatic nucleus neurons and glia in vitro. J Neurosci 12:2648-2664.

Wigglesworth VB (1959) The histology of the nervous system of an insect Rhodnius prolixus (Hemiptera). II. The central ganglia. Q J Microsc Sci 100:229-314

Young MW, Bargiello TA, Baylies MK, Saez I, Spray DC (1989) Molecular biology of the Drosophila clock. In: Neuronal and cellular oscillators (Jacklet JW, ed), pp 529-542. New York: Dekker.

Yu Q, Jacquier AC, Citri Y, Colot HV, Hall JC, Rosbash M (1987) Molecular mapping of point mutations in the period gene that stop or speed up biological clocks in Drosophila melanogaster. Proc Natl Acad Sci USA 84:784-788.

Zerr DM, Rosbash M, Hall JC, Siwicki KK (1990) Circadian fluctuations of period protein immunoreactivity in the CNS and the visual system of Drosophila. J Neurosci 10:2749-2762.

Zwiebel LJ, Hardin PE, Liu X, Hall JC, Rosbash M (1991) A posttranscriptional mechanism contributes to circadian cycling of a per$\beta$-galactosidase fusion protein. Proc Natl Acad Sci USA 88:38823886 . 